\title{
Phenotypic and Molecular Alterations of Potato (Solanum tuberosum L.) cv. 'Cara' as Affected by Benzyl Adenine and Propagation Cycle In Vitro
}

\author{
M.F. Mohamed", B.E.S. Abd El-Fattah" ${ }^{* *}$, Dalia M.T. Nassef *, M.H. Aboul Nasr \\ and Nada N.M. Kandeel* \\ *Department of Vegetable Crops, Faculty of Agriculture, Assiut University Assiut \\ 71526, Egypt and ${ }^{* *}$ Department of Genetics, Faculty of Agriculture, Assiut University \\ Assiut 71526, Egypt.
}

\begin{abstract}
$\mathbf{T}$ he current investigation was carried out in 2016 and 2017 in the Tissue Culture Laboratory of the Department of Vegetable Crops and Biotechnology Laboratory of the Department of Genetics, the Faculty of Agriculture, Assuit University, using the potato cv. Cara. The study assessed the phonotypical alterations and genetic stability using molecular analyses (RAPD, ISSR and SRAP). The stem single node cultures of potato cultivar 'Cara' were followed-up for three shoot multiplication cycles (subcultures) on the medium supplemented with 0.5 or $1.0 \mathrm{mg} / \mathrm{l}$ benzyl adenine (BA) or lacking the BA. Shoots on BA containing medium as compared to that on the medium lacking BA were shorter, developing multiple shoot branches and producing larger number of stem nodes/culture. The stem nodal yield increased by $87.5 \%$ and $131.3 \%$ in cultures on medium supplemented with 0.5 and $1.0 \mathrm{mg} / \mathrm{BA}$, respectively. Cultures of nodal explants derived from shoots propagated on BA containing medium exhibited an interrupted root formation. No roots formed after the second shoot multiplication cycle using nodal explants from shoots formerly grown on medium with $1.0 \mathrm{mg} / \mathrm{l} \mathrm{BA}$. In the third shoot multiplication, cycle rooting did not occur using nodal explants from shoots harvested from cultures on medium with 0.5 or $1.0 \mathrm{mg} / \mathrm{l} \mathrm{BA}$. The molecular assay was confirmatory to the phenotypic assay and the different marker methods used were reliable in assessing tissue culture-induced variations. Overall results are against in vitro use of BA in potato cv. Cara transplant-production media. Check of genetic stability at close intervals is advisable.
\end{abstract}

Keywords: ISSR, Micropropagation, RAPD, SRAP, Soluble protein banding, Transplant production.

\section{Introduction}

Potato (Solanum tuberosum L.) is the most important crop in family Solanaceae and one of the most important crops grown in Egypt for local consumption, export and processing. It is one of the major food crops worldwide and is exceeded only by maize, rice and wheat. Besides its use as food, it is utilized as raw material for processed products, starch and alcohol. In Egypt, the area devoted for potato production as a total of summer, winter and fall seasons in 2015 was estimated by 437386 feddans produced 4955445 metric tons (Bulletin of the Agricultural Statistics, Egyptian Ministry of Agriculture and Land Reclamation).
Potato is commercially a vegetative propagated crop plant. In Egypt, it is grown in three main seasons; summer, winter and fall (Hasan, 1999). Regularly, potato seed tubers are imported for growing summer planting. Tubers produced in summer season are used as seed tubers to grow potato in fall and winter seasons. Imported potato seeds are considerably expensive and present the major cost in summer season production. Tubers produced in fall are highly infected with viral diseases and, therefore, they are not used for further potato production. Besides, conventional vegetative propagation has a low multiplication rate of 1:4 to $1: 15$ depending 
upon the potato cultivar, agro-climatic conditions and crop management practices (Hoque, 2010 and Srivastava et al., 2012). Further, a significant amount of food tubers is vanished when used as seed tubers (3 to 5 metric tones/ha) (Hasan, 1999, Kanwal et al., 2006 and Hoque, 2010). Therefore, costs of planting material in potato are higher than other major food crops. Whereas in the temperate zone cost of healthy seed tubers may represent $20-30 \%$ of the total production costs, in warm climates where constraints of seedtuber based production systems are more serious, seed costs may account for up to $70 \%$ of the total production costs (Upadhya, 1994). Indeed, scarcity of quality seed tubers at affordable prices has been considered the most limiting factor for potato production (Mohapatra and Batra, 2017).

Tissue culture technology for rapid multiplication of disease-free has facilitated the production of healthy potato seed to a great extent (Dodds, 1988 and Mohapatra and Batra, 2017). Rapid multiplication of disease-free clones using micropropagation coupled with conventional multiplication methods has become an integral part of potato tuber seed production programs (Donnelly et al., 2003). Meristem and explants bearing in vivo (preexisting) organized meristems such as shoot tip and single nodes are being effectively employed for in vitro cloning of different plant species (Mohamed et al., 1991 and 1992, Mohamed, 1998, Tawfik and Mohamed, 2005, Tawfik and Mohamed, 2006, and Mohamed et al., 2007 and 2010, ). However, single nodal explants are predominantly employed in potato micropropagation to obtain virus free clones (Liljana et al., 2012 and Mohapatra and Batra, 2017). The proliferated healthy shoots are then used to establish the initial single-nodal explants stock (Naik and Karihaloo, 2007 and Mohapatra and Batra, 2017). These explants are usually cultured on plant growth regulators (PGRs)-free medium to simultaneously proliferating shoots and form roots (Naik, and Karihaloo, 2007 and Struik and Wiersema 2012). Use of medium lacking plant growth regulators (PGRs) would also avoid possible genetic alterations. The obtained plantlets can then be either utilized as an explant source for subsequent propagation cycle or transferred into a microtuber induction medium (Hoque, 2010). Microtubers have tremendous advantages in terms of storage and transportation due to their small size and weight. However, storage of stock explants source plants for up to a year on special medium without subculture has been possible (Mohamed and Tawfik, 2009). The developed microtuber can be

Egypt. J. Hort. Vol. 45, No. 2 (2018) stored and used after breaking dormancy to produce minitubers (Srivastava et al., 2012). Alternatively, the obtained plantlets can be acclimatized ex-vitro to produce transplants which then are grown in an insect proof house to develop minitubers (Mohapatra and Batra, 2017). More recent, an attention is given to transplant production from true potato seeds (Golmirzaie et al., 2004 and Struik and Wiersema, 2012). In all cases, the obtained minitubers are conventionally propagated to produce seed tubers for commercial potato production.

Noticeably, the transplant is the core issue in micropropagation and seed tuber production of potato. Commonly, the in vitro health plantlet can be used for indefinite number of micropropagation cycles. This is most applicable to maintenance of pathogen free plants. However, it is an argument subject especially for polyploidy species as potato and a check for the genetic stability (confirmation of clonal identity) is recommended once a year the least (Naik, and Karihaloo, 2007 and Struik and Wiersema, 2012). A more intensive frequency to assess genomic and gene expression alterations is currently made manageable due to the recent advances in molecular techniques (Ahmad et al., 2018). Another conflicting subject is concerning the PGRs supplements to in vitro nutrient medium to elevate multiplication rate for microshoots from in vitro explants. In this context, researchers have studied the use of cytokinins, particularly, benzyl adenine (BA) in the medium (Kazemiani et al., 2012, Liljana et al., 2012, Fufa and Diro, 2013, Hossain et al., 2013 and Kaur et al., 2015). However, care should be paid to avoid high concentration since potato may suffer genetic alterations and in vitro rooting may be inhibited (Kazemiani et al., 2012). The objective of the current study was to assess the phenotypic performance of in vitro transplants and their genetic stability during consecutive cycles of micropropagation using potato cv. Cara.

\section{Materials and Methods}

This investigation was carried out in 2016 and 2017 in the Tissue Culture Laboratory of the Department of Vegetable Crops and Biotechnology Laboratory of the Department of Genetics, the Faculty of Agriculture, Assuit University. The study was conducted in 2016 and 2017 using the potato cv. Cara to assess its shoot growth and rooting responses toward establishment of in vitro transplants production. 'Cara' is among the most successful potato cultivar grown in Egypt. It is very robust variety, 
extremely high yielding and very uniform. 'Cara' is also a versatile potato suitable for a wide range of culinary uses including chipping. Stem single node cultures for this cultivar were followedup for three subculture cycles on medium supplemented with 0.5 or $1.0 \mathrm{mg} / \mathrm{l}$ benzyl adenine (BA) or lacking the BA. The tubers of this potato cv. were obtained from the Agricultural Research Center, Sohag University.

\section{Explant preparation}

Mother potato tubers were carefully washed under running tap water. They were then surface disinfested using commercial Dettol and 2\% sodium hypochlorite $(\mathrm{NaOCl})$ (prepared utilizing commercial bleach solution, 5\%) plus Tween-20 $(0.25 \mathrm{ml} / \mathrm{l})$ followed by rinsing thoroughly several times with distilled water. The tubers were dried and kept in darkness at $\sim 28^{\circ} \mathrm{C}$ until the initiation of sprouting. Shoot tips (ca. $0.3-0.5 \mathrm{~cm}$ apical stem microcuttings) were excised and surface disinfested by dipping in $70 \%$ ethyl alcohol for one minute then stirred in 1\% sodium hypochlorite $(1: 5 \mathrm{v} / \mathrm{v}$ diluted commercial bleach solution) plus Tween-20 (0.25 $\mathrm{ml} / \mathrm{l}$ ) in laminar air flow hood. The surface disinfested explants were then rinsed thoroughly several times with autoclaved distilled water. The explants were blotted dry on autoclaved paper.

\section{Nutrient medium and establishing of axenic donor plant material}

The prepared explants were vertically cultured on MS medium (Murashige and Skoog, 1962) lacking plant growth regulators (PGR). This medium composed of basal macro-and micro-elements, vitamins, $30 \mathrm{~g} / 1$ sucrose and $7 \mathrm{~g} / \mathrm{l}$ agar. The $\mathrm{pH}$ of the medium was adjusted to $5.8 \pm 0.1 \mathrm{using}$ potassium hydroxide $(\mathrm{KOH})$ or hydrochloric acid $(\mathrm{HCl})$. The medium was subjected to heat while stirred on hot plates to melt the agar. Thirty $\mathrm{ml}$ of the medium were then poured into each $150 \mathrm{ml}$ culture glass jars. Afterward the jars were autoclaved for $20 \mathrm{~min}$ at $120^{\circ} \mathrm{C}$ under $1.2 \mathrm{~kg} / \mathrm{cm}^{2}$. The cultures were placed in the growth room at $28^{\circ} \mathrm{C}$ under $16 \mathrm{~h}$ /day illumination from cool white fluorescent tubes $\left(80 \mu \mathrm{mol} \cdot \mathrm{m}^{-2} \cdot \mathrm{s}^{-1}\right)$. These cultures served as stock donor plants for subsequent study focusing on the assessment of phenotypic and molecular alterations during in vitro transplants production.

\section{In vitro production of transplants}

The donor axenic plants were re-cultured several times on MS medium lacking plant growth regulators tile having enough material to get stem single nodal micro-cuttings for transplant production study. These explants were cultured on medium with 0.5 or $1.0 \mathrm{mg} / 1$ benzyl adenine (BA) or lacking this cytokinin supplement. The employed concentrations of BA were decided based on results of previous reported studies (Kazemiani et al., 2012, Fufa and Diro, 2013, Hossain et al., 2013 and Kaur et al., 2015) and in light of our preliminary assessment.

\section{Phenotypic assay}

The responses of single-nodal explants were assessed 4 weeks after culture and continued for three consecutive subculture cycles of multiplication. A rooting test was conducted on MS medium lacking BA following each multiplication cycle using half random set of the produced shoots. This is to evaluate rooting ability as a necessary step for in vitro transplant production. The remaining half set of the produced shoots was used to run genetic stability test (using molecular markers and soluble protein banding analyses) after each multiplication cycle. The following phonotypical parameters were recorded after each multiplication cycle: branching percent, number of branches, main shoot length and number of harvested stem single nodes (stem single nodal yield). Rooting percent and number of roots/plant were assessed following each rooting test. The experiment was laid out in a complete randomized design (CRD) with four replicates. Each treatment per replicate was presented by 6 jars (one plant/jar). The whole experiment was conducted twice and the average was used in the statistical analyses.

Statistical procedure for phenotypic data analysis

Collected data were processed according to the one-way analysis of variance (ANOVA) corresponding to complete randomized design (CRD). Upon homogeneity of error variances of the separate one way analyses of variance over the three subculture cycles, using Bartlett's test, combined ANOVA was conducted (Gomez and Gomez, 1984). Subculture cycle and BA were considered as fixed variables. Original data were employed for ANOVA. However, transformed data were utilized to get homogenous error variance if not established by the original data. The appropriate mean comparisons (either the main effect or the interaction) were conducted as guided by the respective variance component in combined ANOVA. Means were compared using the Revised Least Significant Difference (LSD) at $\mathrm{P} \leq 0.05$. The LSD statistical test was based on transformed means if used in ANOVA. It is calculated only for the means of the significant variance components. Furthermore, the Euclidean distance matrix and cluster analysis for 6 phenotypic traits were performed using computer program NTSYS-pc ver. 2.1 (Rolhf, 2000).

\section{Molecular assays \\ DNA extraction}

Plant DNA was extracted from fresh leaves 
of donor potato plants and the proliferated shoots from three cycles of subculture on MS media supplemented with different concentrations of BA using Cetyl trimethyl ammonium bromide (CTAB)-based procedure (Murray and Thompson, 1980) with some modifications. Concentration and quality of DNA was measured at $260 \mathrm{~nm}$ using a spectrophotometer and checked by separating DNA on $0.8 \%$ agarose gel.

Primers and DNA markers (RAPD, ISSR and SRAP detection)

A total of fourteen RAPD, sixteen ISSR and fourteen SRAP primers or primer pairs, obtained from Metabion International AG, were used in PCR amplification. Table 1 shows the sequences found for polymorphic primers. PCR procedures were carried out in a Lab Cycler (Model SensoQuest, GmbH, Germany). PCR reaction was carried out in a $25 \mu \mathrm{l}$ total volume containing $11.7 \mu \mathrm{d}_{2} \mathrm{O}, 3.0 \mu \mathrm{l} 10 \mathrm{X}$ reaction buffer, $3.0 \mu \mathrm{l}$ dNTP's mix, $2.0 \mu \mathrm{l}$ primer for RAPD or ISSR, $1.0 \mu \mathrm{L}$ of each of forward and reveres primer for SRAP, $4.0 \mu \mathrm{lggCl}_{2}, 0.3 \mu \mathrm{l} \mathrm{Taq}$ DNA polymerase and $1 \mu \mathrm{l}$ Template DNA.

RAPD and ISSR amplification conditions were as follows: an initial denaturation at $94^{\circ} \mathrm{C}$ for 5 min ( $1^{\text {st }}$ step), 45 cycles of 1 min denaturation at $92^{\circ} \mathrm{C}, 1 \mathrm{~min}$ annealing at $32-34^{\circ} \mathrm{C}$ for RAPD and $38-44{ }^{\circ} \mathrm{C}$ for ISSR) and 2 min extension at $72^{\circ} \mathrm{C}\left(2^{\text {nd }}\right.$ step $), 10 \mathrm{~min}$ final extension at $72^{\circ} \mathrm{C}\left(3^{\text {rd }}\right.$ step), then followed by a final hold at $4^{\circ} \mathrm{C}$. The SRAP amplification program was: $3 \mathrm{~min}$ initial denaturation at $94{ }^{\circ} \mathrm{C} ; 10$ cycles consisting of 1 $\min$ at $94^{\circ} \mathrm{C}, 1 \mathrm{~min}$ at $35^{\circ} \mathrm{C}$, and $1.5 \mathrm{~min}$ at $72^{\circ} \mathrm{C}$; 35 cycles consisting of $1 \mathrm{~min}$ at $94{ }^{\circ} \mathrm{C}, 1 \mathrm{~min}$ at $50{ }^{\circ} \mathrm{C}$, and $1.5 \mathrm{~min}$ at $72{ }^{\circ} \mathrm{C}$; and a final $10 \mathrm{~min}$ at $72{ }^{\circ} \mathrm{C}$. Amplification products were separated on agarose gel $1.4 \%, 2 \%$ and $2.5 \%$ for RAPD, ISSR and SRAP, respectively. The DNA bands were visualized using Gel DOOC-IT2 Imager.

RAPD, ISSR and SRAP data analyses

For each primer the presence (1) or absence (0) of DNA bands in each genotype was visually scored and entered into a binary matrix. The pairwise comparisons between the tested genotypes were used to calculate the coefficient of genetic similarity matrix (Gs) according to Dice (1945). A dendrogram was constructed based on similarity estimates using NTSYS-pc version 2.11T (Rolhf, 2000). The mantel test (Mantel, 1967) used to calculate the correlation between the molecular marker systems and also calculate the correlation between molecular markers and phenotypic traits.

TABLE 1. Polymorphic primer codes and sequences used in RAPD, ISSR and SRAP analyses.

\begin{tabular}{|c|c|}
\hline Primer codes & Primer sequences \\
\hline \multicolumn{2}{|c|}{ RAPD } \\
\hline OPA01 & 5'-CAG GCC CTT C-3' \\
\hline UBC09 & 5'-CCTGCGCTTA-3' \\
\hline OPA13 & 5'-CAGCACCCAC-3' \\
\hline OPA07 & 5'-GAAACGGGTG-3' \\
\hline OPD02 & 5'-GGACCCAACC-3' \\
\hline \multicolumn{2}{|c|}{ ISSR } \\
\hline HB15 & 5'-GTGGTGGTGGC-3' \\
\hline HB08 & 5'-GAG AGA GAG AGA GG-3' \\
\hline HB12 & 5'-CACCACCACGC-3' \\
\hline HB & 5'-CAC ACA CAC ACA AC-3' \\
\hline HB10 & 5'-GAG AGA GAG AGA CC-3' \\
\hline \multicolumn{2}{|r|}{ SRAP } \\
\hline \multirow{2}{*}{ SRAP-1 } & 5'-ATTCAAGGAGAGTGCGTGG-3' \\
\hline & 5'-TTTCAGGAGCAGATGGTGG-3' \\
\hline \multirow{2}{*}{ SRAP-2 } & 5'-GACTGCGTACGAATTCAAT-3' \\
\hline & 5'-TTGGTAACTTGGACTTGTGG-3' \\
\hline \multirow{2}{*}{ SRAP-3 } & 5'-TCAAGGGCAGGTAAGAACAA-3' \\
\hline & 5'-GTCAAAGAAGGCTCAAGGCA-3' \\
\hline \multirow{2}{*}{ SRAP-4 } & 5'-ТСАТСТСАААССАТСТАСАС-3' \\
\hline & 5'-AGTTGGACATTATTGGCAGC-3' \\
\hline \multirow{2}{*}{ SRAP-5 } & 5'-GTGAGGAGTGATGTCCGT-3' \\
\hline & 5'-TCGTCACGGATCATTTCTCT-3' \\
\hline
\end{tabular}

Egypt. J. Hort. Vol. 45, No. 2 (2018) 


\section{Soluble protein banding}

Polyacrylamide gel electrophoresis

The electrophoresis was carried out in vertical polyacrylamide gels, using the slab gel apparatus "SE 600, vertical slab gel". Polyacrylamide gel electrophoresis was carried out according to Laemmli (1970) with $12 \%$ acrylamide $+1.0 \%$ SDS for protein analysis.

\section{Preparation of samples}

Protein was extracted by crushing $1.0 \mathrm{~g}$ of sample tissue in $1.0 \mathrm{ml}$ extraction buffer $(0.1$ $\mathrm{M}$ Tris- $\mathrm{HCl}+2$ mM EDTA, $\mathrm{pH} 7.8)$. Then, the samples were centrifuged for 25 minutes at 10.000 $\mathrm{rpm}$ and $4^{\circ} \mathrm{C}$. One hundred microliters of the supernatant was mixed by one hundred microliter of sample application buffer $(2.5 \mathrm{mM}$ Tris- $\mathrm{HCl}$ pH 6.8, $10.0 \%$ glycerol, $4.0 \%$ SDS, $0.02 \%$ bromophenol blue and $10 \%$ mercaptoethanol). Then, the samples were incubated in water path at $100{ }^{\circ} \mathrm{C}$ for five minutes for protein denaturation, then loaded in the electrophoresis.

\section{Protein staining and identification}

Proteins were staining 4 hours with Comassie Brilliant Blue $(0.025 \%$ Comassie Brilliant Blue R- 250, $40 \%$ methanol and $7 \%$ acetic acid). Then, gels were distained for one hour in a mixture of $50 \%$ methanol and $10 \%$ acetic acid. Thereafter, the gels were transferred to a destainer filled with $7 \%$ acetic acid and $5 \%$ methanol until the background is clear. Data were obtained by scanning densitometer GS 300 (Hoffer) of protein profiles. The molecular weights of protein bands were determined against protein marker $(116,66$, 45, 35, 25, 18.4 and 14.4 KDa), using GS 365 electrophoresis data system programm version 3.01 (Microsoft Windows @ version).

\section{Results}

In a preliminary study, concentration of BA higher than $1 \mathrm{mg} / \mathrm{l}$ gave rosette structure and verification. Consequently, these cultures gave no excisable shoots (Fig. 1). Under such conditions, usually associated callus formation was observed. Therefore, the subsequent critical assessment was conducted using BA concentrations of 0.5 and $1.0 \mathrm{mg} / 1$.

\section{Phenotypic assay}

Shoot characterization (branching and main shoot length)

Branching percents for the BA concentrations (Fig. 2A), shoot proliferation culture cycles (Fig. 2B) and their different combinations (Fig. 2C) along with the partitioning of total variance are presented in Figure 2. ANOVA revealed that neither the subculture cycles nor its interaction with BA had significant effect on branching percent. In contrary, BA showed a clear significance and was the major component of the total variance. The meaningful mean comparisons (ANOVA data) are, therefore, among BA main effect (Fig. 2A). Overall, 0.5 and $1.0 \mathrm{mg} / \mathrm{l} \mathrm{BA}$ in the medium induced branching in $100 \%$ and $91.7 \%$, respectively, of the cultures. Medium lacking BA showed $32.4 \%$ of the cultures developing axillary shoots. As illustrated in Figure 2, the difference between branching on medium containing $0.5 \mathrm{mg} / \mathrm{l}$ and $1.0 \mathrm{mg} / 1$ was not significant. On medium containing no BA, significantly lower branching percent was detected.

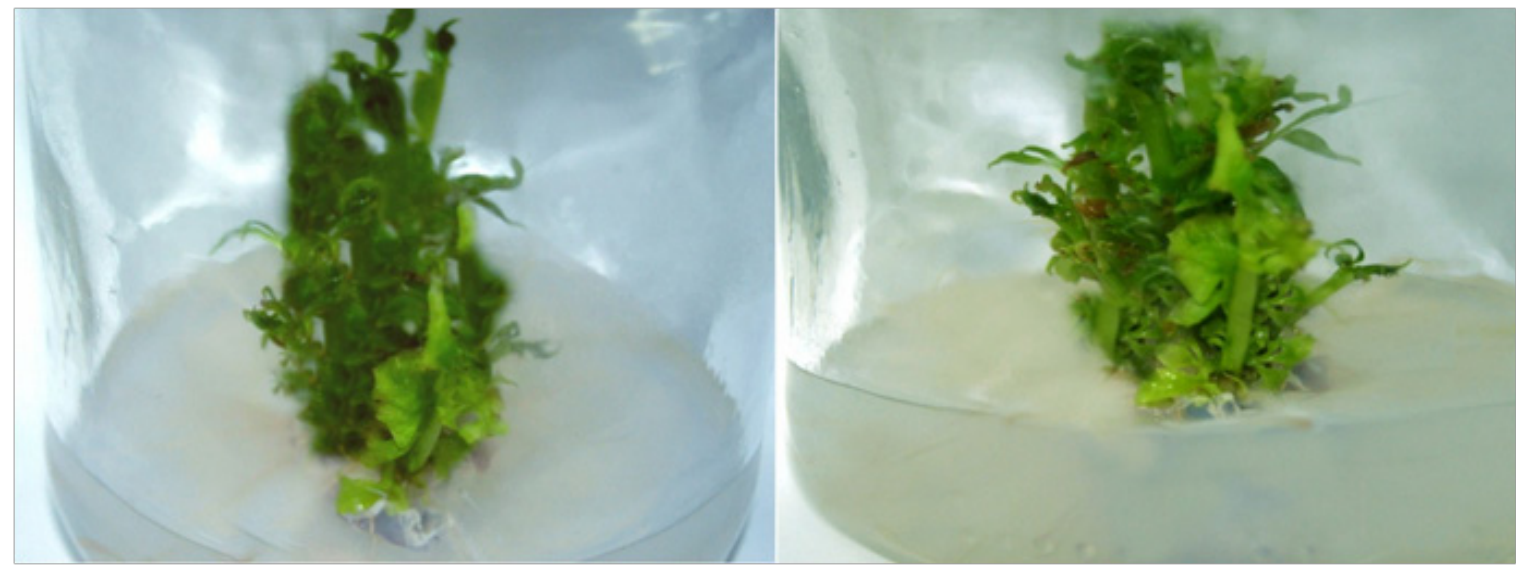

Fig. 1. Rosette structure and vitrification occurred in higher concentration of BA than $1 \mathrm{mg} / \mathrm{l}$. 


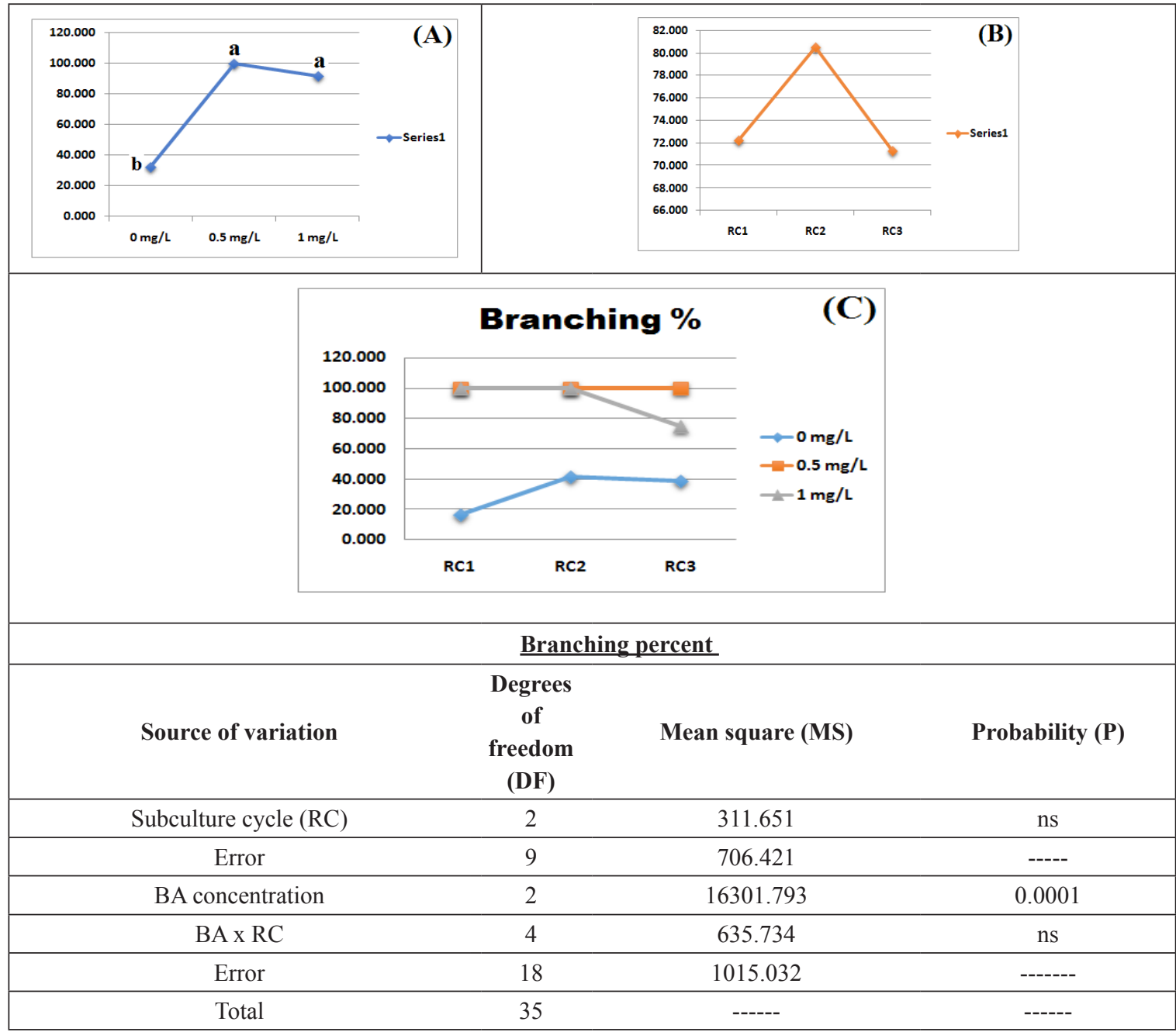

Fig. 2. Means of shoot branching percent of potato (Solanum tuberosum L.) grown in vitro as affected by (A) three different concentrations of benzyl adenine (BA) in the medium and three sequential cycles of subculture (B) and their interactions (C).Mean comparisons are made only for those component of variance achieving significance as shown in combined analysis of variance (ANOVA). Means denoted the same small letter(s) are not significantly different using the Revised Least Significant Difference (LSD) Test at 0.05 level of probability, ns=insignificant.

Figure 3 presents the means of branch number for the BA treatment (Fig. 3A) and the subculture cycle (Fig. 3B) plus means of factorial combinations of BA and the subculture cycle (Fig. 3C). The different components of total variation for branch number are also presented. Subculture cycle did not exert appreciable effect on the number of axillary branches. Similarly, its interaction with BA was insignificant. Evidently, BA seemed to be the foremost component of the total variance. The appropriate and meaningful mean comparisons (ANOVA data) are, therefore, among BA main effect treatments (Fig. 3A). Adding 0.5 or 1.0 $\mathrm{mg} / \mathrm{l} \mathrm{BA}$ to the medium induced 2.4 to 2.9 axillary shoots, respectively, with no significant difference Egypt. J. Hort. Vol. 45, No. 2 (2018) between the two BA concentrations. Medium with no BA added showed, on average, a value of 0.5 for developed axillary shoots.

Figure 4 exhibits the means of main shoot length for different BA treatments (Fig. 4A), subculture cycles (Fig. 4B) and their factorial combinations (Fig. 4C). The partitions of the total variance for main shoot length in accordance to combined ANOVA over subculture cycles are also shown. Evidently, there was a great significant variance due to benzyl adenine (BA) treatments and subculture cycle. No significant variance due to the interaction of benzyl adenine (BA) treatments and subculture cycle was found. Mean 
comparisons (Fig. 4A) show reduced main shoot length for cultures on medium with $1.0 \mathrm{mg} / \mathrm{l} \mathrm{BA}$ in comparisons with the medium having $0.5 \mathrm{mg} / 1 \mathrm{BA}$. Medium lacking BA and medium having $0.5 \mathrm{mg} / \mathrm{l}$ BA were comparable. Regarding the subculture cycles (Fig. 4B), shoots produced in the second subculture cycle were taller than those obtained in the first and third cycles. The latter two subculture cycles were comparable concerning this parameter.

Single nodal segments yield

Figure 5 presents the means of single nodal segments yielded for BA (Fig. 5A) and the subculture cycle (Fig. 5B) plus means of factorial combinations of BA and the subculture cycle (Fig. 5C). Different components of total variation are also presented. Subculture cycle did not exert appreciable effect on the number of nodes/culture (single nodal segment yield). The interaction between the subculture cycle and BA was not significant. Evidently, BA seemed to be the principal component of the total variance. The meaningful mean comparisons (ANOVA data) are, therefore, among BA main effect treatments (Fig. 5A). Addition of $1.0 \mathrm{mg} / \mathrm{l} \mathrm{BA}$ to the medium produced the largest number of nodes/culture followed by adding $0.5 \mathrm{mg} / \mathrm{l} \mathrm{BA}$. Medium with no BA added showed the least number of nodes/culture.

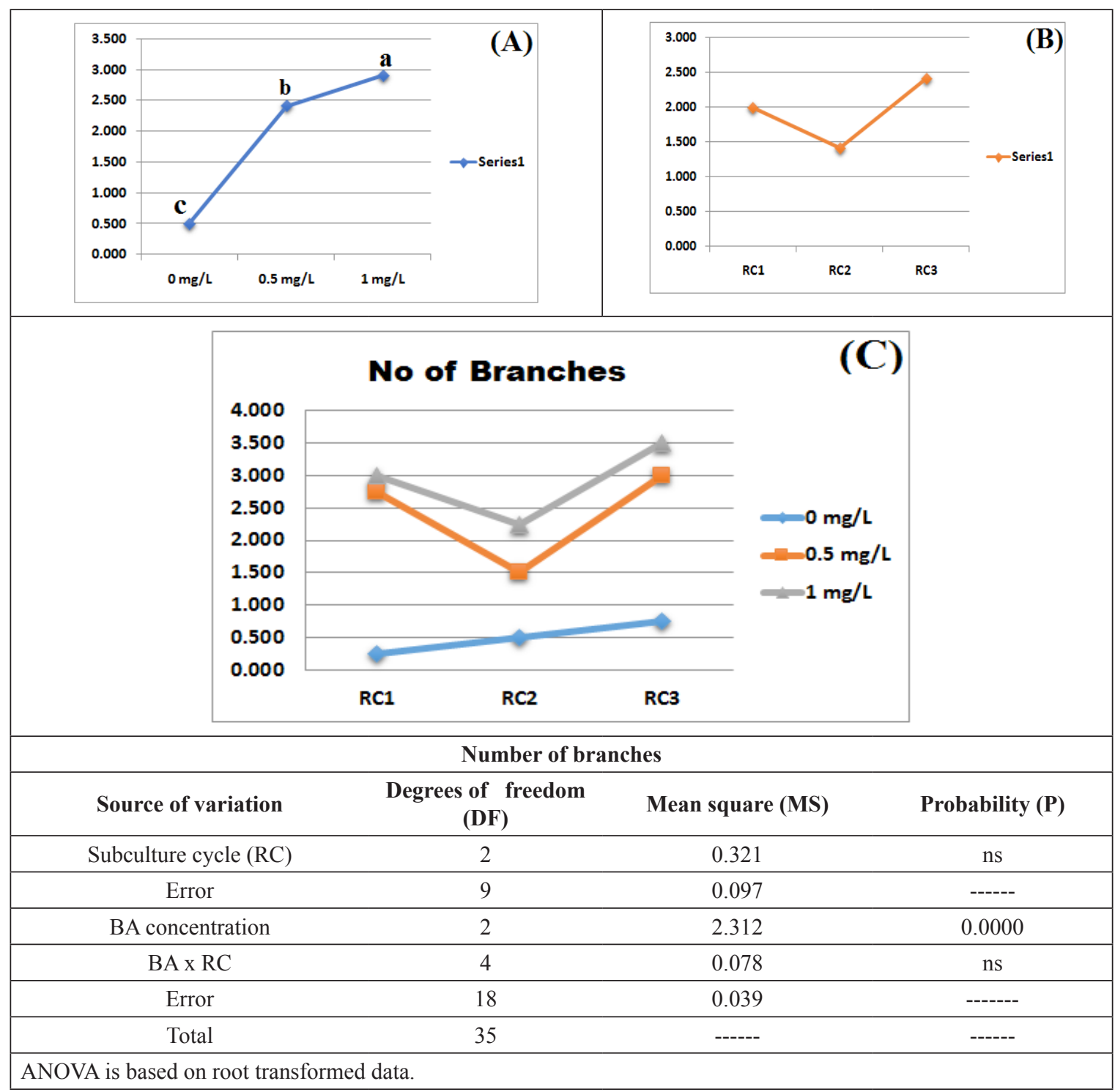

Fig. 3. Means of the number of branches of potato (Solanum tuberosum L.) grown in vitro as affected by (A) three different concentrations of benzyl adenine (BA) in the medium and three sequential cycles of subculture (B) and their interactions $(\mathrm{C})$. Mean comparisons are made only for those component of variance achieving significance as shown in combined analysis of variance (ANOVA). Means denoted the same small letter(s) are not significantly different using the Revised Least Significant Difference (LSD) Test at 0.05 level of probability, ns=insignificant. 


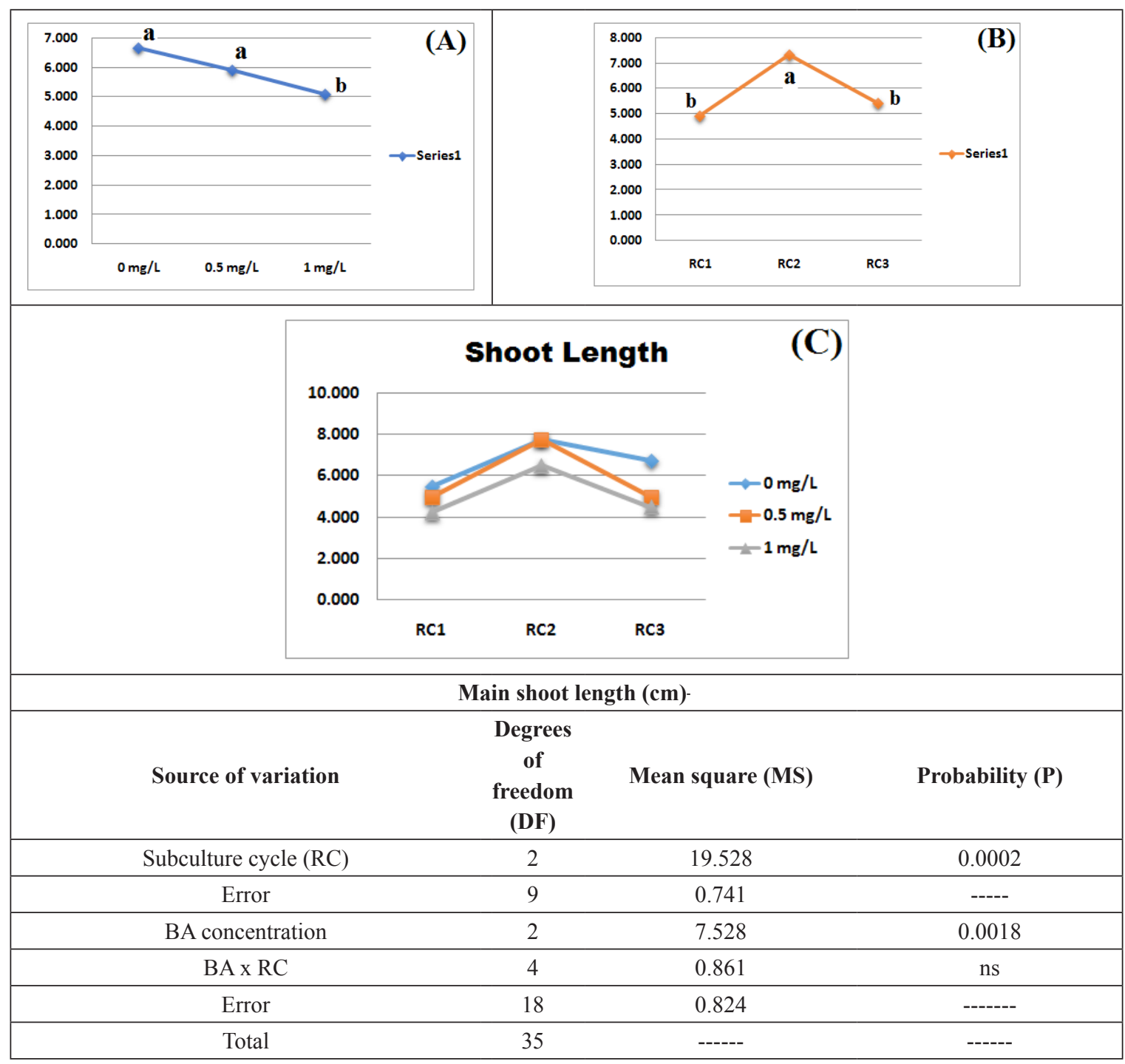

Fig. 4. Means of main shoot length of potato (Solanum tuberosum L.) grown in vitro as affected by (A) three different concentrations of benzyl adenine (BA) in the medium and three sequential cycles of subculture (B) and their interactions (C). Mean comparisons are made only for those component of variance achieving significance as shown in combined analysis of variance (ANOVA). Means denoted the same small letter(s) are not significantly different using the Revised Least Significant Difference (LSD) Test at 0.05 level of

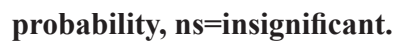

\section{Rooting percent}

As shown by ANOVA data in Fig. 6, it is clear that both BA treatments and subculture cycles had significant effect on rooting percent. On the contrary, BA interaction with subculture cycles had no significant effect (Fig. 6C). The appropriate mean comparisons (ANOVA data) are, therefore, among means of BA main effect (Fig. 6A) and subculture cycle main effect (Fig. 6B). Addition of $1.0 \mathrm{mg} / \mathrm{l} \mathrm{BA}$ to the medium significantly reduced rooting percent. Medium with no BA added or with $0.5 \mathrm{mg} / 1 \mathrm{BA}$ supplement were comparable and showed elevated rooting percent. Similar tendency occurred concerning the subculture cycle. Rooting

Egypt. J. Hort. Vol. 45, No. 2 (2018) percent was comparable in the first and second subculture cycles. However, significant reduction was detected in the third subculture cycle.

\section{Number of roots/plantlet}

The error variances relevant to the three separate one way analyses of variance for subculture cycles were not homogenous even when used transformed data (Bartlett's test; $\chi^{2}=11.497^{* *}$ ). The combined analysis of variance for the number of roots/plant was, therefore, conducted only over the first and second subculture cycles $\left(\chi^{2}=2.846 \mathrm{~ns}\right)$. It is apparent that BA treatments had significant effect on root number. A significantly reduced number of 


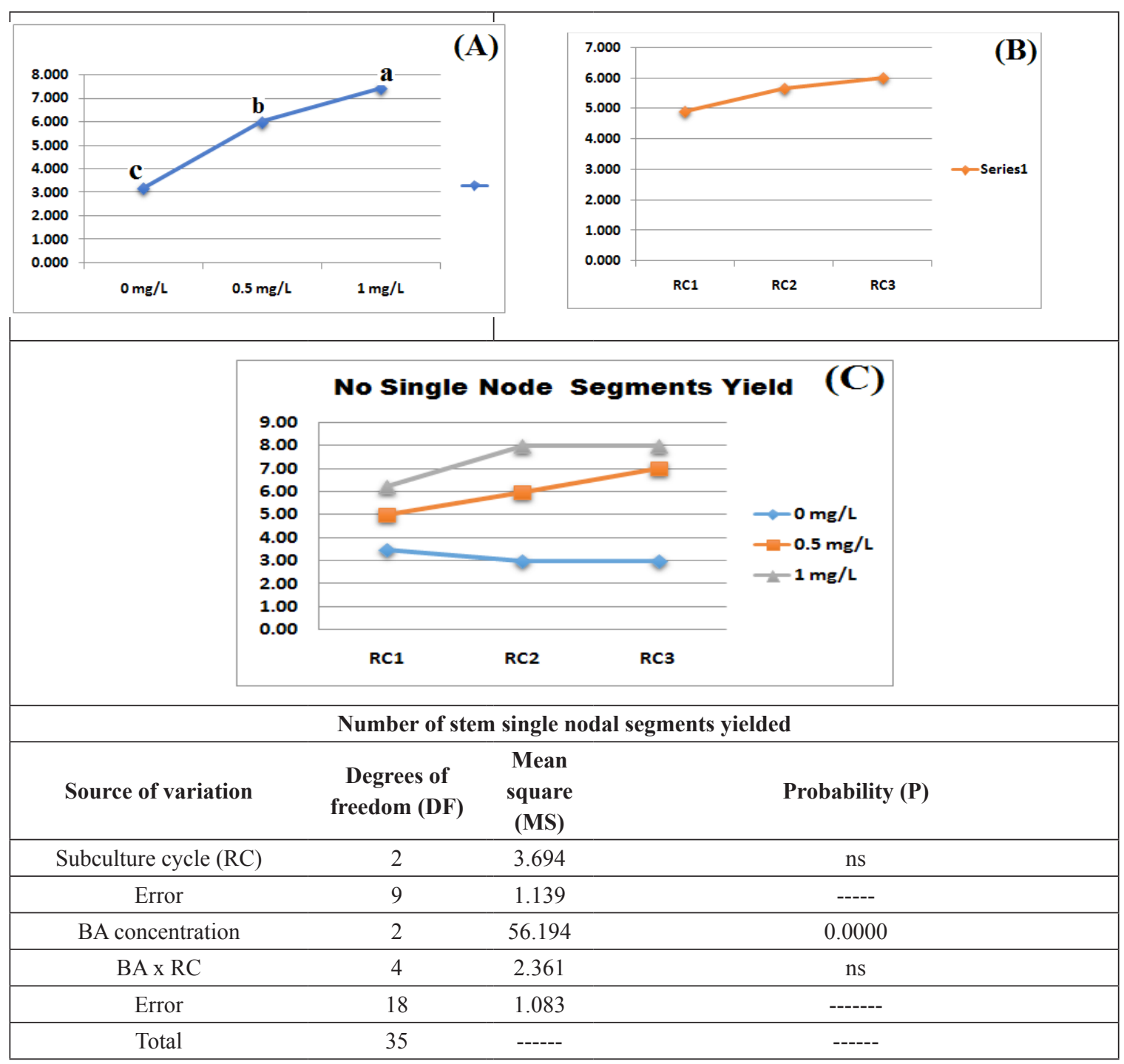

Fig. 5. Means of stem single nodal segment yield of potato (Solanum tuberosum L.) grown in vitro as affected by (A) three different concentrations of benzyl adenine (BA) in the medium and three sequential cycles of subculture (B) and their interactions (C). Mean comparisons are made only for those component of variance achieving significance as shown in combined analysis of variance (ANOVA). Means denoted the same small letter(s) are not significantly different using the Revised Least Significant Difference (LSD) Test at 0.05 level of probability, ns=insignificant.

roots/plant was detected for shoots derived from the medium with $1 \mathrm{mg} / \mathrm{l} \mathrm{BA}$ compared to those shoots derived from the medium with or without $0.5 \mathrm{mg} / \mathrm{l}$ BA in the first two subculture cycles (Fig. 7A). The difference between the first two subculture cycles did not achieve significance (Fig. 7B; ANOVA data). In the second subculture cycle (Fig 7C, Fig. 8), no roots were observed for shoots resultant from the medium with $1 \mathrm{mg} / \mathrm{l} \mathrm{BA}$ added. Roots on shoots derived from the medium containing 0.5 $\mathrm{mg} / \mathrm{l} \mathrm{BA}$ or lacking it did not significantly differ $(\mathrm{LSD}=0.43)$.
In the third subculture cycle, no rooting occurred on shoots derived from the medium with $0.5 \mathrm{mg} / \mathrm{l}$ and with $1 \mathrm{mg} / \mathrm{l} \mathrm{BA}$ added (Fig. 7C). Those shoots formerly grown on the medium without BA supplements had reduced but significantly greater number of roots/plant $\left(\mathrm{t}=5.82^{* *}\right)$. In contrary, both subculture cycles and BA interaction with subculture cycles had no significant effect. In general, the combined analysis of variance accentuates the severe reduction for roots number on shoots formerly grown on medium supplemented with elevated concentrations of BA. 


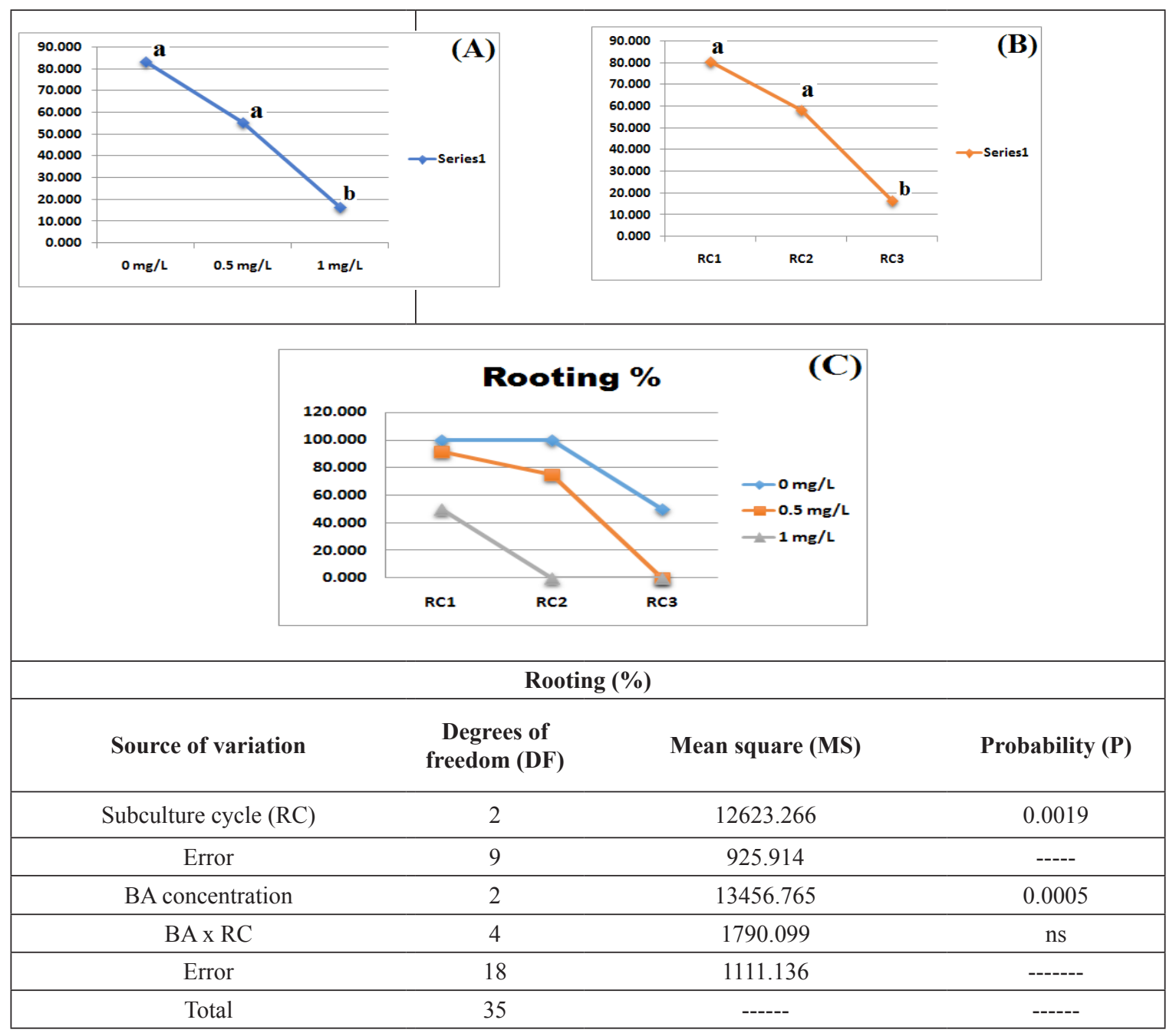

Fig. 6. Means of rooting percent of potato (Solanum tuberosum L.) grown in vitro as affected by (A) three different concentrations of benzyl adenine (BA) in the medium and three sequential cycles of subculture (B) and their interactions (C). Mean comparisons are made only for those component of variance achieving significance as shown in combined analysis of variance (ANOVA). Means denoted the same small letter(s) are not significantly different using the Revised Least Significant Difference (LSD) Test at 0.05 level of probability, ns=insignificant.

Associations among the studied parameters

The fifteen correlation coefficients (r) calculated between different pairs of the studied traits are listed in Table 2. Seven (r) values achieved significance. The obtained data show significant and positive correlations between number of branches and branching percent, between number of nodes/plant and each of branching percent and number of branches and between number of roots/plant and rooting percent. On the contrary, main shoot length was negatively correlated with number of branches. Also, significant and negative correlations were detected between rooting percent and each of number of branches and number of nodes/plant.
Euclidean distance and cluster analysis of phenotypic data

The dissimilarity matrix of the Euclidean distance using six phenotypic traits between all pairs of entries ranged from 0.16 between donor plant (D) and plants proliferated in subculture-1 on MS control medium (0.0 BA) media (A1) to 5.16 between plant regenerated from subculture-3 on MS media with $1.0 \mathrm{mg} / \mathrm{l} \mathrm{BA} \mathrm{(C3)} \mathrm{and} \mathrm{each}$ of donor plant (D) and plant proliferated from subculture-1 on MS control medium (A1). The range of Euclidean distance among all genotypes was relatively wide. A dendrogram generated from the standardized phenotypic data is presented in Figure 9. The dendrogram divided

Egypt. J. Hort. Vol. 45, No. 2 (2018) 


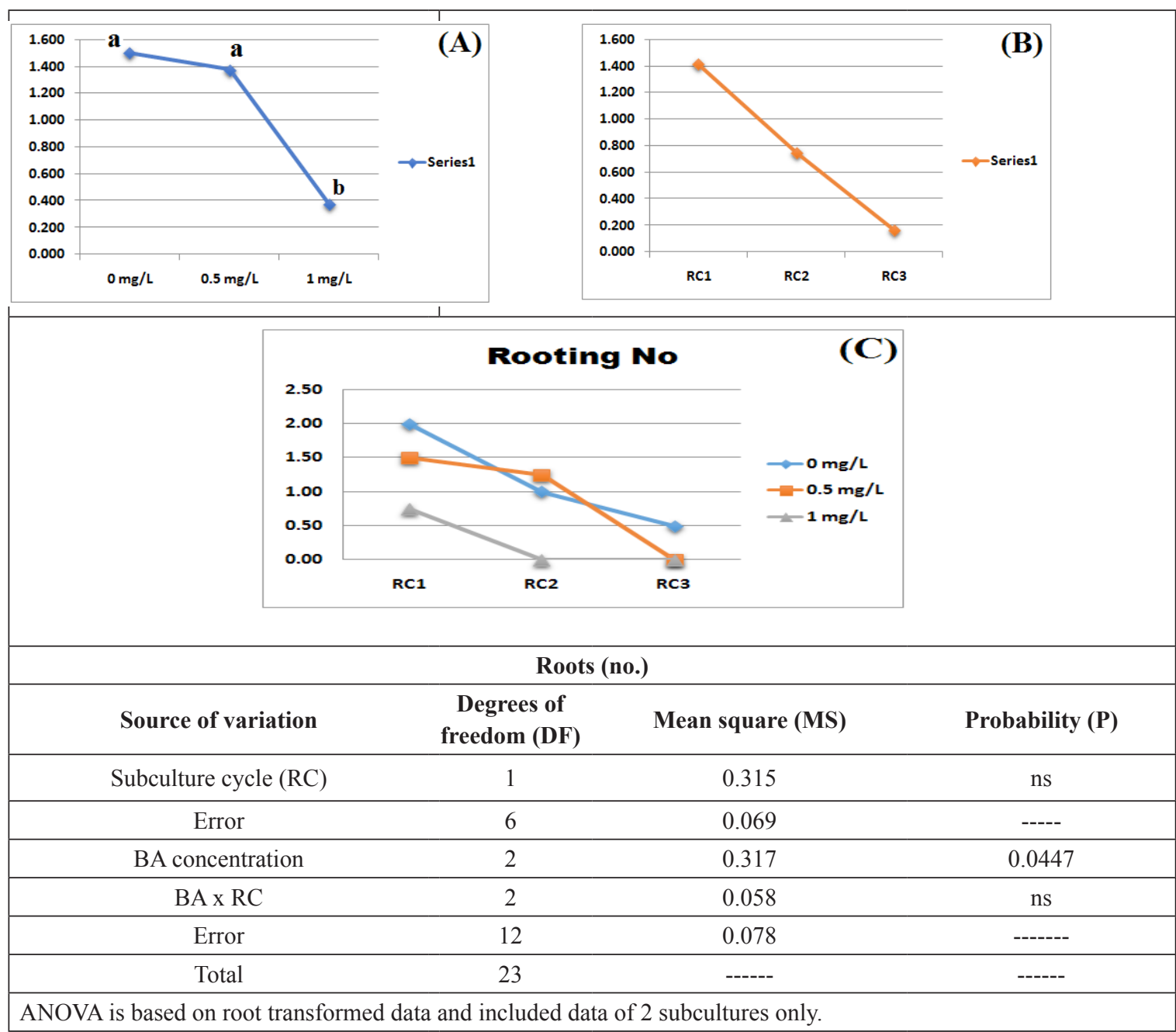

Fig. 7. Means of number of roots/plantlet of potato (Solanum tuberosum L.) grown in vitro as affected by (A) three different concentrations of benzyl adenine (BA) in the medium and three sequential cycles of subculture (B) and their interactions (C). Mean comparisons are made only for those component of variance achieving significance as shown in combined analysis of variance (ANOVA). Means denote the same small letter(s) are not significantly different using the Revised Least Significant Difference (LSD) Test at 0.05 level of probability, ns=insignificant.

(A)

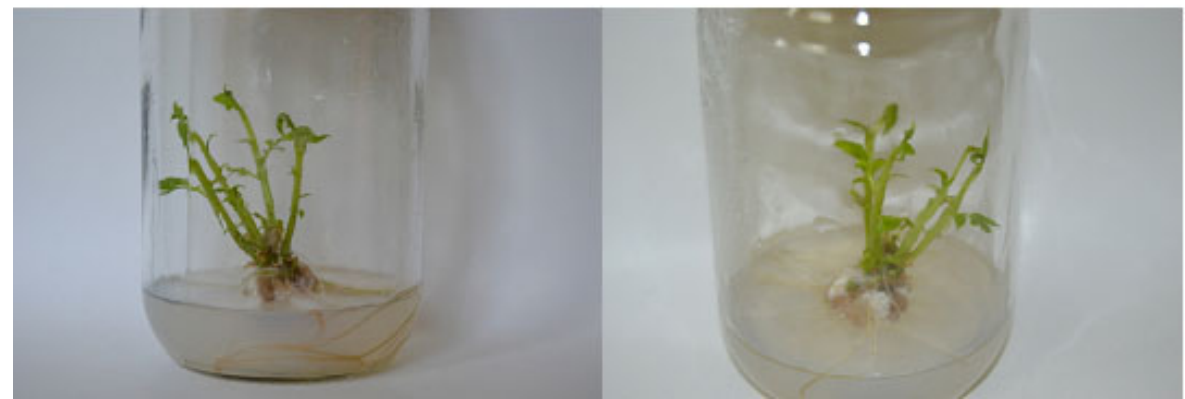

Fig. 8. Root formation on medium lacking benzyl adenine (BA) following the second propagation cycle (rooting test): (A) roots in cultures established from stem nodal explants of shoots formerly propagated on medium with $0.5 \mathrm{mg} / \mathrm{l} \mathrm{BA}$ added while $(\mathrm{B})$ cultures developing no roots in the same propagation cycle when using explants formerly multiplicities on medium supplemented with $1 \mathrm{mg} / \mathrm{l}$ BA.

Egypt. J. Hort. Vol. 45, No.2 (2018) 
the donor plant and all regenerated plants into four clusters. Cluster-1 includes the donor plant and all proliferated plant from three cycles of subculture on MS control medium (A1, A2 and A3). Cluster-2 contains only plants proliferated from subculture- 2 on MS media with $0.5 \mathrm{mg} / 1 \mathrm{BA}$ (B2). Cluster-3 comprises plants proliferated in the first cycle of sub-culture on MS media with 0.5 and $1.0 \mathrm{mg} / 1 \mathrm{BA}$ (B1 and $\mathrm{C} 1$, respectively). Cluster-4 contains plants proliferated from subculture-3 (B3 and C3) in additions to plants proliferated from subculture-2 (C2) on MS media with $1.0 \mathrm{mg} / \mathrm{l} \mathrm{BA}$ which is separated in a single branch from $\mathrm{B} 3$ and $\mathrm{C} 3$.

Fig. 9. Dendrogram based on six phenotypic traits (branching percent, number of branches, main shoot length, number of harvested stem single nodes, rooting percent and number of roots/plant) generated using Euclidian distance coefficient of the donor plant and the proliferated shoots on different media $(0,0.5$ and $1.0 \mathrm{mg} / \mathrm{l}$ benzyl adenine) and three different subculture cycles.

\section{Molecular marker assays}

TABLE 2. Simple correlation coefficients (r) among the studied traits of potato (Solanum tuberosum L.) grown in vitro on medium containing $0,0.5$ and $1.0 \mathrm{mg} / \mathrm{l}$ benzyladenine (BA) for three sequential cycles of subculture.

\begin{tabular}{|l|c|c|c|c|c|}
\hline \multicolumn{1}{|c|}{ Trait } & Branching \% & No. branches & $\begin{array}{c}\text { Main shoot } \\
\text { length }\end{array}$ & No. nodes/plant & Root \% \\
\hline No. branches & $0.793^{* *}$ & & & & \\
\hline Main shoot length & -0.262 & $-0.704^{*}$ & & & \\
\hline No. nodes/plant & $0.761^{*}$ & $0.833^{* *}$ & -0.425 & & $-0.807^{* *}$ \\
\hline Root \% & -0.407 & $-0.665^{*}$ & 0.360 & -0.646 & $0.927^{* *}$ \\
\hline No. roots/plant & -0.405 & -0.563 & 0.165 & & \\
\hline
\end{tabular}

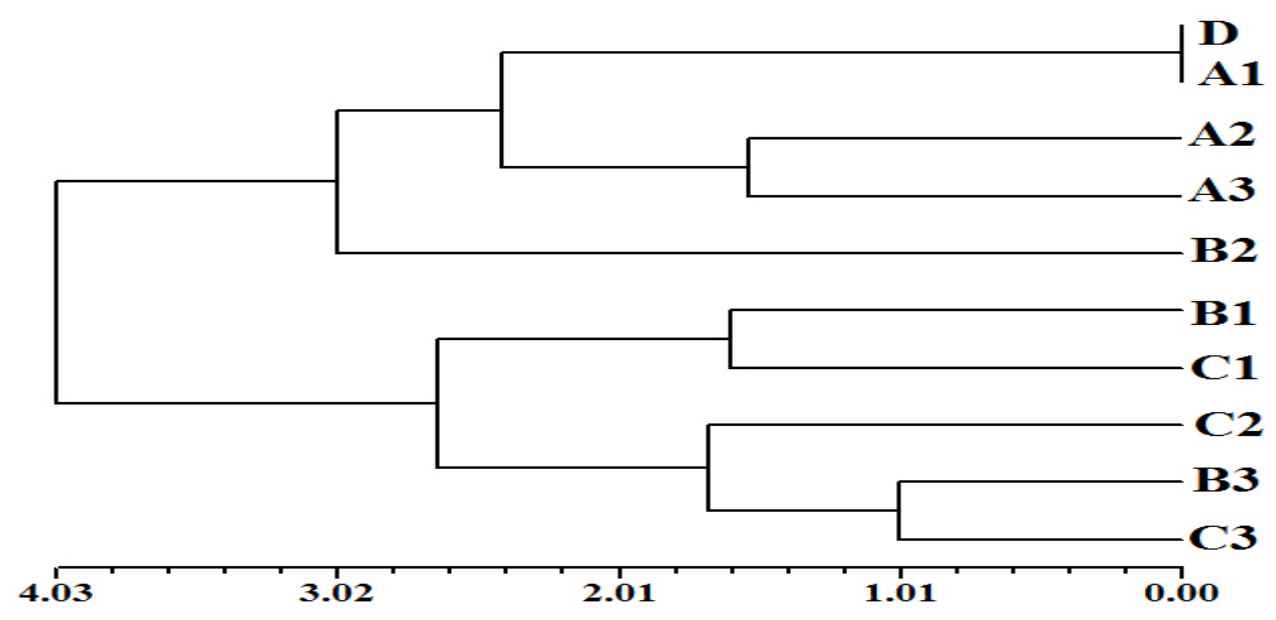

Fig. 9. Dendrogram based on six phenotypic traits (branching percent, number of branches, main shoot length, number of harvested stem single nodes, rooting percent and number of roots/plant) generated using Euclidian distance coefficient of the donor plant and the proliferated shoots on different media $(0,0.5$ and $1.0 \mathrm{mg} / \mathrm{l}$ benzyl adenine) and three different subculture cycles.

Egypt. J. Hort. Vol. 45, No. 2 (2018) 
Five RAPD, five ISSR and five SRAP primers or primer combinations gave polymorphic bands and reproducible results that were further considered for data analysis. Distinct differences in the reproducible bands obtained from tissue culture regenerated plants are shown in three clear profiles of agarose gel (Fig. 10, 11 and 12).

\section{RAPD analysis}

A total of 49 DNA fragments were amplified by RAPD from different plant entries. RAPD-PCR products were in the molecular size range from 142 bp (OPA07) to $1478 \mathrm{bp}$ (OPA01) with an average of 9.8 fragments per RAPD primer (Fig. 10a-e). Out of the 49 fragments scored, 12 bands $(24.49 \%)$ were found to be polymorphic and 37 loci $(75.51 \%)$ were found to be monomorphic in nature with an average of 2.4 polymorphic bands per primer (Table 3). The polymorphism percentage ranged between $8.33 \%$ (for OPA13) and $37.5 \%$ (for UBC09). The polymorphic information content (PIC) values for the five RAPD primers varied from 0.04 (OPA13) to 0.13 (OPA01). The marker index (MI) values ranged from 0.04 (OPA13) to 0.38 (OPA01). The resolving power of primer (RP) values ranged from 0.6 to 1.4 , the OPD02 primer gave the highest RP values (1.4) while OPA13 exhibited the lowest $\mathrm{RP}$ value (0.6) (Table 3 ). The genetic similarity between the donor plant and the proliferated plants ranged from 1.0 between regenerated plants from sub-culture-2 on MS control medium (A2) and proliferated plants from sub-culture-3 on MS control medium (A3) to 0.86 between the donor plant and proliferated plants from subculture- 3 on $1 \mathrm{mg} / 1 \mathrm{BA}(\mathrm{C} 3)$.

The dendrogram divided the ten entries into two major groups (Fig. 10f). Group-1 included donor plant, regenerated plants from the three cycles of sub-cultures on MS control medium (A1, A2and A3) and regenerated plants from the first and second cycles of sub-culture (B1) and (C1) on MS media supplemented with $0.5 \mathrm{mg} / \mathrm{l}$ and $1.0 \mathrm{mg} / 1 \mathrm{BA}$, respectively. Within this group, the donor plant (D) and regenerated plants from the three cycles of subculture on control medium (A1, A2 and A3) were grouped together in cluster-1 with a genetic similarity of 0.979 , while regenerated plants from sub-culture-1 on different concentration of BA (B1 and C1) were grouped in cluster-2 with a genetic similarity of 0.987 .

Group-2 comprised regenerated plant from subculture-2 (B2 and C2) and subculture-3 (B3 and C3) on MS with different concentrations of BA. This group divided the proliferated plants from subculture-2 and sub-culture- 3 into two clusters based on the concentrations of $\mathrm{BA}$, where the proliferated plants from subculture-2 (B2) and sub-culture-3 (B3) on MS supplemented with $0.5 \mathrm{mg} / \mathrm{l} \mathrm{BA}$ were grouped together in cluster-1 with a genetic similarity of 0.965 , while regenerated plants from subculture-2 (C2) and subculture-3 (C3) on MS supplemented with $0.1 \mathrm{mg} / 1 \mathrm{BA}$ were grouped together in cluster-2 with a genetic similarity of 0.968 (Fig. 10f).

\section{ISSR analysis}

The five ISSR primers amplified a total of 36 DNA fragments from different plant entries. ISSRPCR products were in the molecular size ranged from $141 \mathrm{bp}$ (HB08) to $920 \mathrm{bp}$ (HB15) with an average of 7.2 fragments per ISSR primer (Fig. 11a-e). Out of the 36 fragments scored, 14 bands $(38.89 \%)$ were found to be polymorphic with an average of 2.8 polymorphic bands per primer (Table 3 ). The polymorphism percentage ranged from $20.0 \%$ (for HB12) to $71.43 \%$ (for HB15). The PIC values varied from 0.06 (HB12) to 0.26 (HB15). The MI values ranged from 0.13 (HB12) to 1.31 (HB15). The RP values ranged from 2.8 to 0.4 , the HB15 primer gave the highest RP values (2.8) while HB exhibited the lowest RP value (0.4) (Table 3).

The genetic similarity ranged from 1.0 between donor plant (D) and proliferated plants from subculture-1 on MS control medium (A1), proliferated plants from sub-culture- $1 \mathrm{on} 1.0 \mathrm{mg} / \mathrm{l}$ $\mathrm{BA}(\mathrm{C} 1)$ and proliferated plants from subculture-2 on control medium (A2), proliferated plants from subculture-2 on $0.5 \mathrm{mg} / 1 \mathrm{BA}(\mathrm{B} 2)$ and proliferated plants from subculture- 3 on control medium (A3) to 0.836 between proliferated plants from subculture-3 on $1 \mathrm{mg} / \mathrm{l} \mathrm{BA}(\mathrm{C} 3)$ and each of proliferated plants from subculture-3 on control medium (A3) and regenerated plants from subculture-2 on $0.5 \mathrm{mg} / \mathrm{l} \mathrm{BA}$ (B2).

The dendrogram divided the ten entries into two major groups (Fig. 11f). Group-1 divided into two main clusters, cluster- 1 comprises donor plant and all proliferated plants from subculture-1 on MS with different concentrations of BA (A1, $\mathrm{B} 1$ and $\mathrm{C} 1)$ in addition to proliferated plants from subculture-2 on control medium (A2), within this cluster, donor plant is closely related to proliferated plants on control medium. While proliferated plants on MS supplemented with 0.5 mg BA was separated in a single branch with a genetic similarity of 0.948 . Also proliferated plants of the first sub-culture on MS with $1.0 \mathrm{mg} / \mathrm{l}$ BA (C1) was closely related to proliferated plants from subculture-2 (A2) with a genetic similarity of 0.962 . Cluster- 2 comprises proliferated plants from subculture-2 on different concentrations of BA (B2, C2) and proliferated plants from subculrure-3 on control medium (A3). Within this cluster, proliferated plants (B2) are closely related to proliferated plants (A3). Group-2 included proliferated plants from subculture-3 (B3 and C3) which proliferated on MS media supplemented with 0.5 and $1.0 \mathrm{mg} / \mathrm{l} \mathrm{BA}$, respectively (Fig. 11f). 


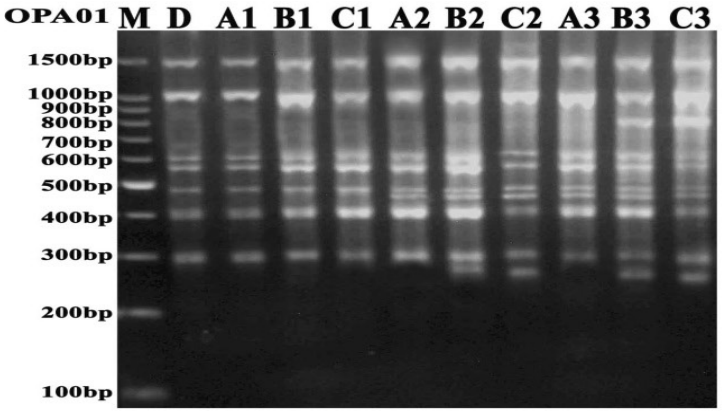

(a)

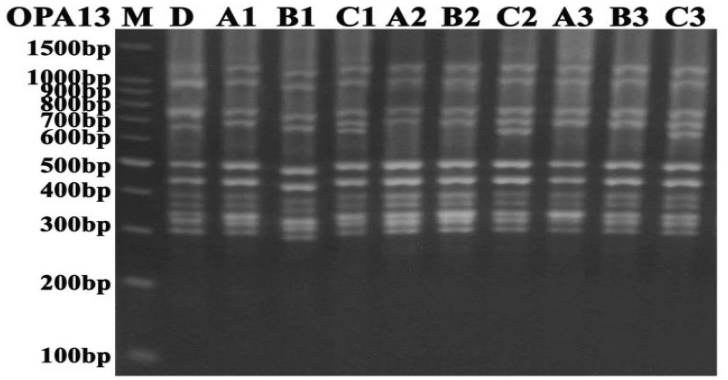

(c)

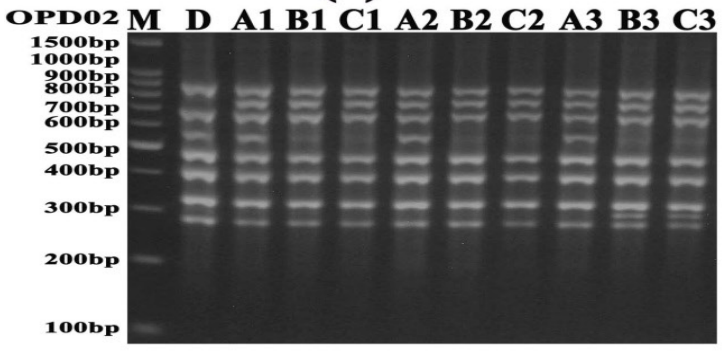

(e)

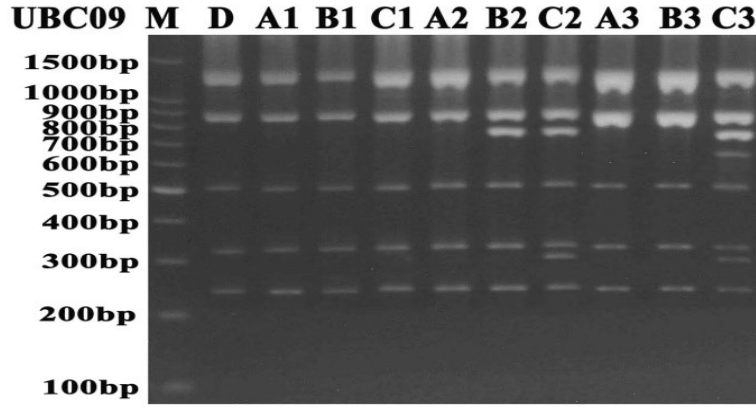

(b)

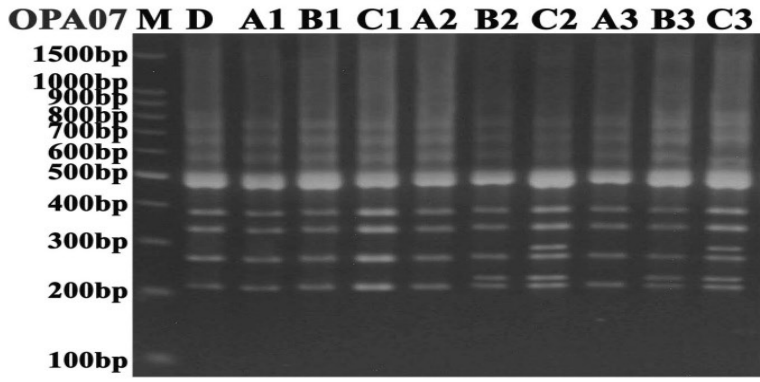

(d)

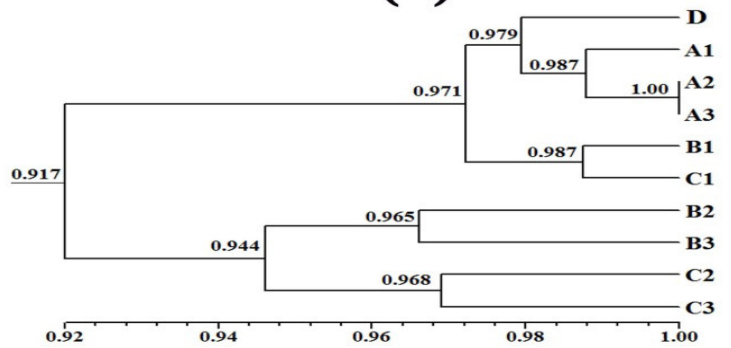

(f)

Fig. 10. RAPD banding profile of potato donor plant (D) and the proliferated plant from three cycles of subculture (A1, B1, C1, A2, B2, C2, A3, B3 and C3). Lane M represented the DNA ladder. The dendrogram developed from five RAPD primers data using UPGMA analysis. The scale is based on Dice coefficients of similarity.

\section{SRAP analysis}

The five SRAP primer combinations amplified a total of 42 DNA bands from donor plant and all regenerated plants with an average of 8.4 bands per primer. Amplified fragments ranged in size from $134 \mathrm{bp}$ (SRAP-4) to $718 \mathrm{bp}$ (SRAP-2) (Fig. $12 \mathrm{a}-\mathrm{e})$. Out of the 42 fragments scored, 16 bands (38.1\%) were found to be polymorphic with an average of 3.2 polymorphic loci per primer (Table $3)$. The polymorphism percentage ranged between $25.0 \%$ (for SRAP-4) to $44.44 \%$ (for SRAP-1 and SRAP-5). The PIC values for five SRAP primers varied from 0.08 (SRAP-4) to 0.18 (SRAP-2). The MI values ranged from 0.16 (SRAP-4) to 0.66 (SRAP-1). The RP values ranged from 2.4 (SRAP-1 and SRAP-2) to 0.8 (SRAP-4) (Table 2). The genetic similarity ranged from 1.0 between donor plant (D) and proliferated plants from subculture-1 on control medium (A1) to 0.783 between regenerated plants from sub-culture- 3 on $1 \mathrm{mg} / \mathrm{l} \mathrm{BA}$ at (C3) and each of donor plant (D) and regenerated plants from subculture on control medium (A1).

The dendrogram divided the ten genotypes into two major groups (Fig. 12f). Group-1 is divided to three clusters; cluster-1 contains donor plant (D), and proliferated plants from subculture-1 and subculture-2 on control medium (A1) and (A2), respectively. In this cluster, donor plant was closely related to proliferated plant (A1). Cluster-2 included proliferated plant from subculture-1 (B1) and (C1). proliferated plant from sub-culture-3 on control MS medium (A3) 


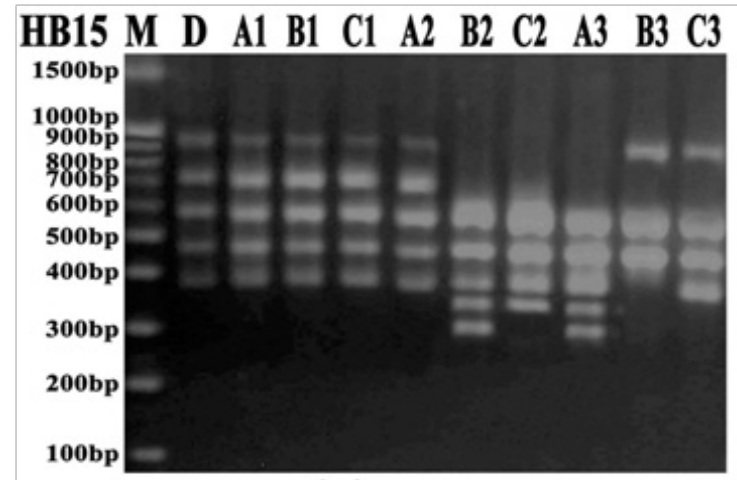

(a)

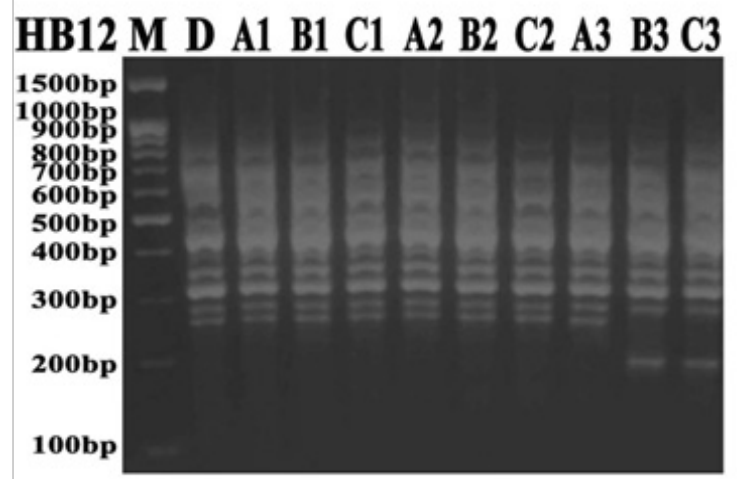

(c)

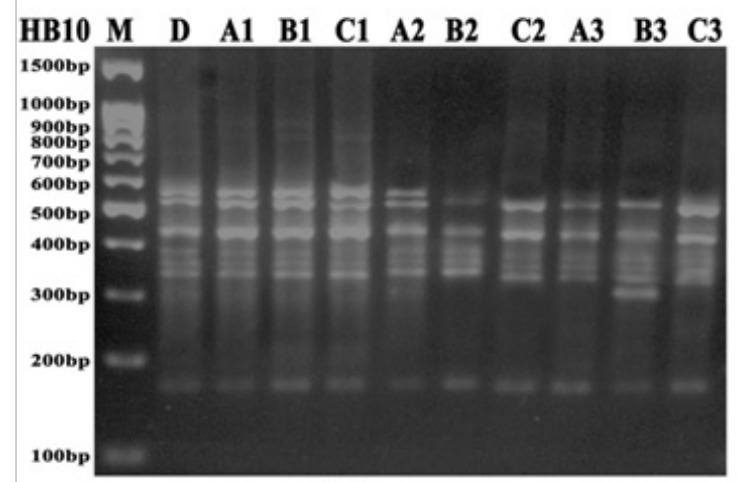

(e)

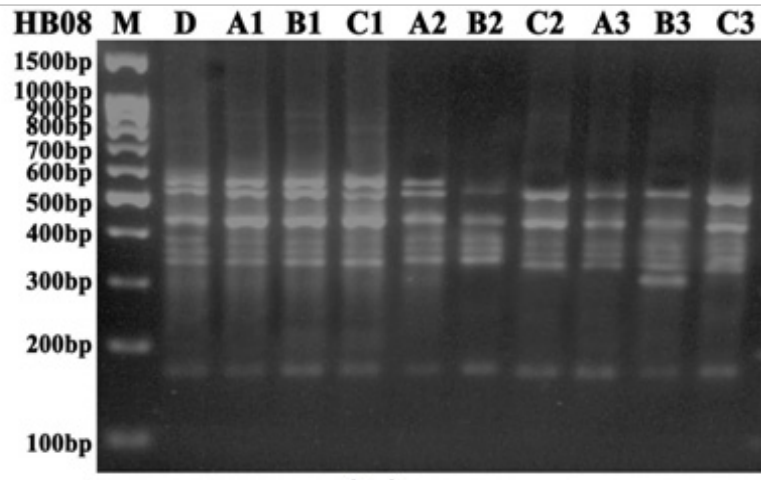

(b)

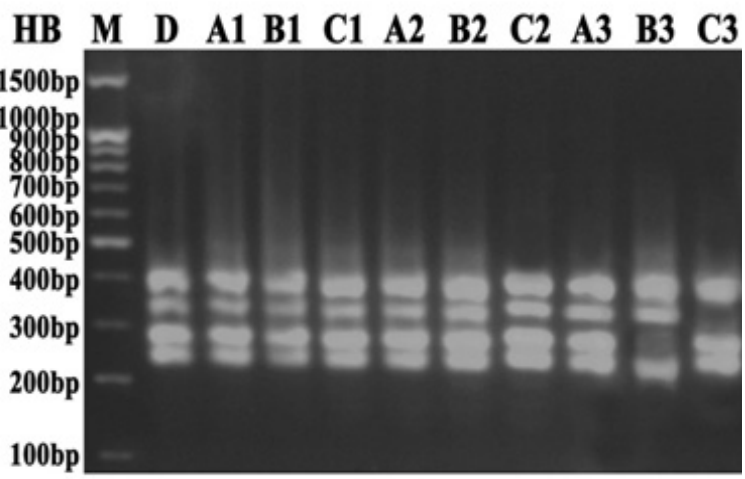

(d)

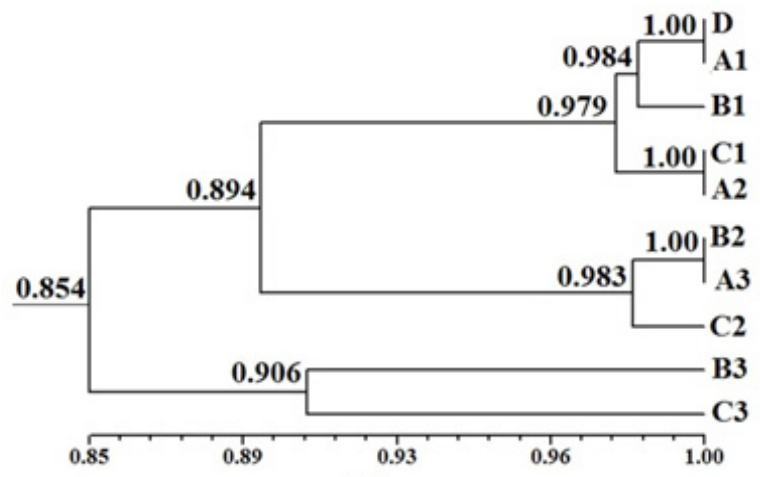

(f)

Fig. 11. ISSR banding profile of potato donor plant (D) and the proliferated plant from three cycles of subculture (A1, B1, C1, A2, B2, C2, A3, B3 and C3). Lane M represented the DNA ladder. The dendrogram developed from five ISSR primers data using UPGMA analysis. The scale is based on Dice coefficients of similarity.

was separated in a single branch from the other entries in group-1 with genetic similarity 0.95 . Group-2 is divided into two clusters. Cluster-1 comprises proliferated plants from the second and the third subcultures on MS medium contained 0.5 mg/l BA from subculture-2 (B2) and subculture-3
(B3) with a genetic similarity of 0.946 while cluster-2 comprises of proliferated plants from the second and the third subcultures on MS medium contained $1 \mathrm{mg} / \mathrm{l} \mathrm{BA}(\mathrm{C} 2)$ and $(\mathrm{C} 3)$ with a genetic similarity of 0.941 (Fig 12f).

Egypt. J. Hort. Vol. 45, No.2 (2018) 


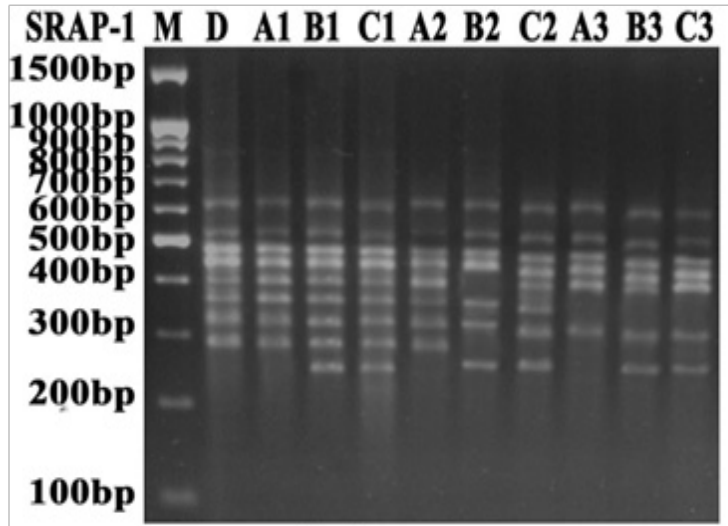

(a)

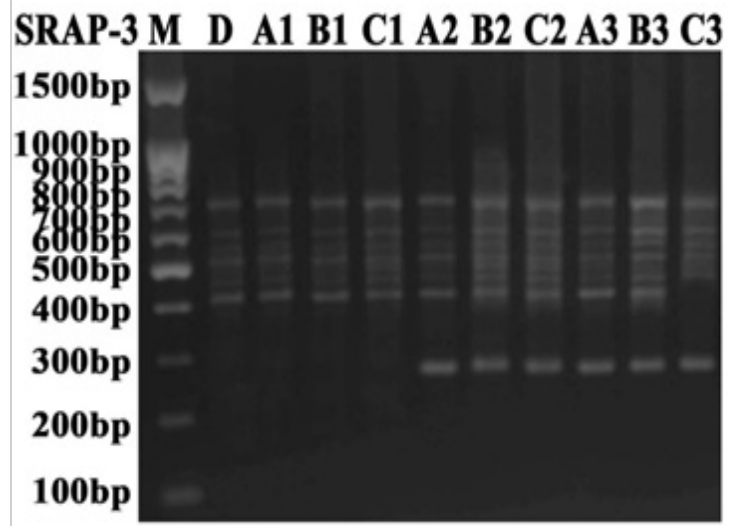

(c)

SRAP-5 M D A1 B1 C1 A2 B2 C2 A3 B3 C3

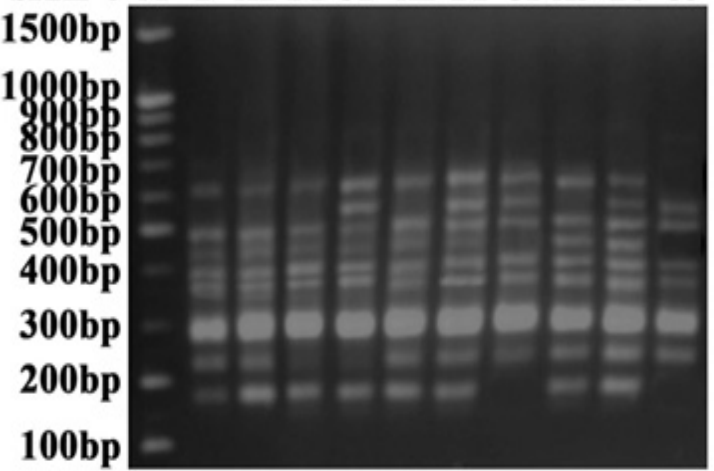

(e)

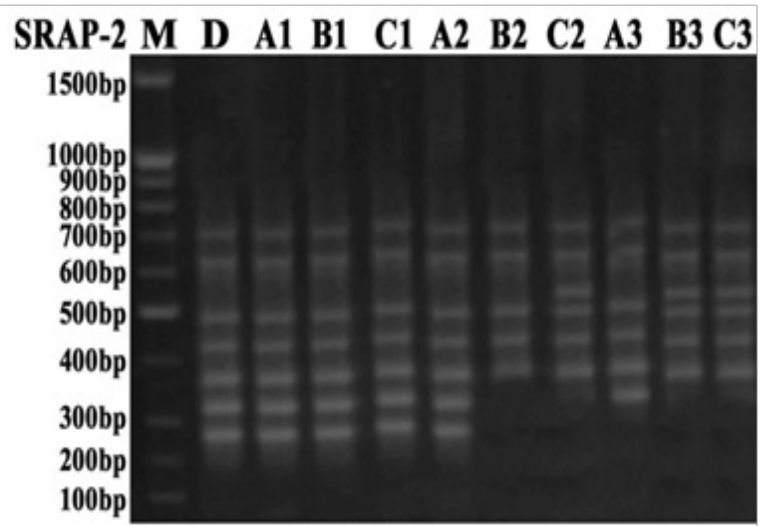

(b)

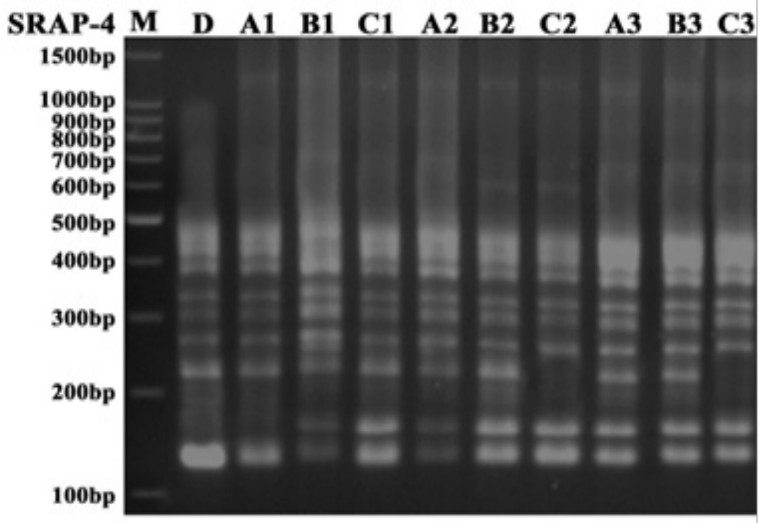

(d)

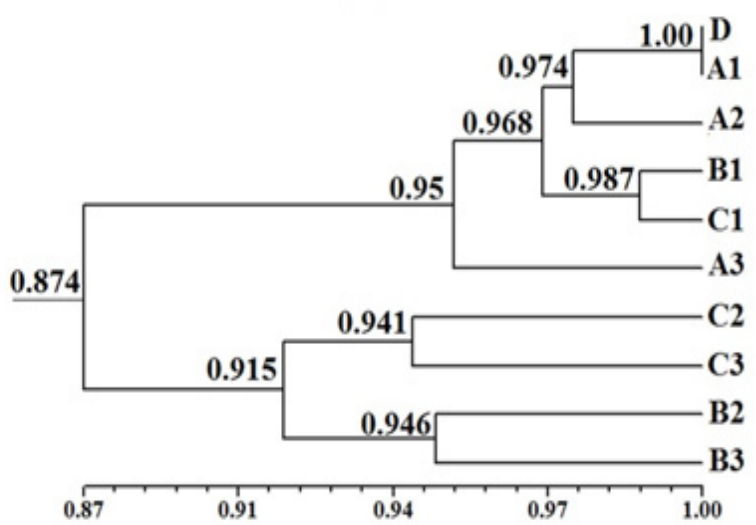

(f)

Fig. 12. SRAP banding profile of potato donor plant (D) and the proliferated plant from three cycles of subculture (A1, B1, C1, A2, B2, C2, A3, B3 and C3). Lane M represented the DNA ladder. The dendrogram developed from five SRAP primers data using UPGMA analysis. The scale is based on Dice coefficients of similarity. 
TABLE 3. Parameters of genetic variation generated using RAPD, ISSR and SRAP DNA markers ${ }^{(1)}$

\begin{tabular}{|c|c|c|c|c|c|c|c|}
\hline & Primers & TB & PB & PPB & PIC & MI & $\mathbf{R P}$ \\
\hline \multirow{7}{*}{ 定 } & OPA1 & 10 & 3 & 30 & 0.13 & 0.38 & 2 \\
\hline & UB09 & 8 & 3 & 37.5 & 0.12 & 0.35 & 1.2 \\
\hline & OPA13 & 12 & 1 & 8.33 & 0.04 & 0.04 & 0.6 \\
\hline & OPA07 & 10 & 2 & 20 & 0.08 & 0.16 & 1.2 \\
\hline & OPD02 & 9 & 3 & 33.3 & 0.11 & 0.33 & 1.4 \\
\hline & Total & 49 & 12 & -- & -- & -- & -- \\
\hline & Avereage & 9.8 & 2.4 & 25.8 & 0.09 & 0.25 & 1.28 \\
\hline \multirow{8}{*}{$\begin{array}{l}\widetilde{\tilde{U}} \\
\tilde{\mathscr{\Omega}}\end{array}$} & Primers & TB & PB & PPB & PIC & MI & $\mathrm{RP}$ \\
\hline & HB15 & 7 & 5 & 71.43 & 0.26 & 1.31 & 2.8 \\
\hline & HB08 & 7 & 3 & 42.86 & 0.19 & 0.56 & 2.2 \\
\hline & HB12 & 10 & 2 & 20 & 0.06 & 0.13 & 0.8 \\
\hline & $\mathrm{HB}$ & 4 & 2 & 50 & 0.09 & 0.18 & 0.4 \\
\hline & HB10 & 8 & 2 & 25 & 0.1 & 0.21 & 1.4 \\
\hline & Total & 36 & 14 & - & - & - & - \\
\hline & Avereage & 7.2 & 2.8 & 41.86 & 0.14 & 0.48 & 1.52 \\
\hline \multirow{8}{*}{$\frac{2}{\sqrt{2}}$} & & TB & PB & PPB & PIC & MI & $\mathrm{RP}$ \\
\hline & SRAP-1 & 9 & 4 & 44.44 & 0.16 & 0.66 & 2.4 \\
\hline & SRAP-2 & 8 & 3 & 37.5 & 0.18 & 0.53 & 2.4 \\
\hline & SRAP-3 & 8 & 3 & 37.5 & 0.12 & 0.37 & 1.4 \\
\hline & SRAP-4 & 8 & 2 & 25 & 0.08 & 0.16 & 0.8 \\
\hline & SRAP-5 & 9 & 4 & 44.44 & 0.15 & 0.59 & 2 \\
\hline & Total & 42 & 16 & -- & -- & -- & -- \\
\hline & Average & 8.4 & 3.2 & 37.78 & 0.14 & 0.46 & 1.8 \\
\hline
\end{tabular}

\footnotetext{
(1) $\mathrm{TB}=$ Total Bands, $\mathrm{PB}=$ Polymorphic Bands, PIC= polymorphic information content, MI= Marker Index, RP= Resolving Power
}

\section{Combined molecular markers data}

A total of 127 DNA fragments were generated from donor plant and all proliferated plants from the three cycles of sub-culture on MS media with different concentration of BA using three molecular markers (RAPD, ISSR and SRAP). Out of these fragments, 42 bands $(33.07 \%)$ were polymorphic. The genetic similarity based on combined data ranged from 0.995 between donor plant (D) and regenerated plants from subculture-1 on control medium (A1) to 0.834 between donor plant (D) and proliferated plants from subculture-3 on $1 \mathrm{mg} / 1 \mathrm{BA}$ (C3).

The dendrogram constructed based on similarity matrix of combined molecular markers data divided all entries into three clusters (Fig. 13). Cluster-1 included donor plant (D) and all proliferated plant from the first cycle of subculture on all cultures media (A1, B1 and C1) in additions to proliferated plant from the second cycle of sub-culture on control MS medium (A2). This cluster divided into two sub-clusters; subcluster-1 contains donor plant and proliferated plants from subculture-1 and subculture- 2 on MS control medium (A1 and A2, respectively), subcluster-2 includes proliferated plants from subculture-1 on MS media with $0.5 \mathrm{mg} / 1$ and $1.0 \mathrm{mg} / 1 \mathrm{BA}$ (B1 and $\mathrm{C} 1$, respectively). Cluster-2 contains the proliferated plants from the second cycle of subculture on MS media contains 0.5 and $1.0 \mathrm{mg} \mathrm{BA} / 1$ (B2 and C2 plants, respectively) in addition to the regenerated plant from the third cycle of subculture on MS BA-free medium (A3 plants). Cluster-3 contained the proliferated plants from the third cycle of subculture on media contained 0.5 and $1.0 \mathrm{mg} \mathrm{BA} / 1$ (B3 and C3 plants, respectively) (Fig. 13).

The Mantel test values between Dice similarity matrices of molecular markers showed significant correlations, RAPD + ISSR $(r=0.57851)$, RAPD + SRAP $(r=0.95403)$, ISSR + SRAP $(r=00.68748)$ and (RAPD+ISSR+SRAP $(r=0.85469)$ which indicated a good agreement between RAPD, ISSR and SRAP markers.

Egypt. J. Hort. Vol. 45, No.2 (2018) 


\section{Soluble protein banding analysis}

Out of 16 protein bands detected, 12 bands were common in donor plant and all regenerated plants from the three cycles of sub-culture (Table 4 and Fig. 14a) while 4 bands (25\%) were polymorphic. Protein band of molecular weight 69.8 KD was detected in the donor plant, all regenerated plants from subculture-1 (A1, B1 and $\mathrm{C} 1)$ and plants proliferated from subculture 1 and 2 on MS control medium (A2 and A3). This band was not expressed in plants regenerated from the second and third cycle of sub-culture on MS media contained 0.5 or $1.0 \mathrm{mg} / 1 \mathrm{BA}$.

Protein band of molecular weight at 50.8 KD expressed only in proliferated plant from the second and third cycle of subculture on both MS media contained 0.5 and $1.0 \mathrm{mg} / \mathrm{l} \mathrm{BA}$. The electrophoresis revealed also that protein band at 38.0 KD appeared only in plants proliferated on MS media contained BA through three cycles of sub-culture, while not appeared in donor plant and all proliferated plants from three cycles of subculture on MS media without BA. Protein band at 25.2 KD was detected in donor plant and all proliferated plants except those generated from subculture- 3 on MS media contained 0.5 or 1.0 $\mathrm{mg} / \mathrm{l} \mathrm{BA}$. The genetic similarity ranged from 0.857 to 1.0 and the dendrogram divided the ten entries into two major groups (Fig 14b). Group-1 included the donor plant, all regenerated plant from three cycles of sub-culture on MS control medium and plant proliferated from sub-culture-1 on MS containing 0.5 and $1.0 \mathrm{mg} / \mathrm{l} \mathrm{BA}$. Within this group the donor plants were closely related to all proliferated plants from three cycles of subculture on control medium. Group-2 comprises proliferated plants from the second and third cycles of subculture on MS media containing 0.5 and $1.0 \mathrm{mg} / \mathrm{l} \mathrm{BA}$.

The Mantel test values between distance matrices of phenotypic matrices and combined matrices of molecular markers and biochemical markers showed positive and significant correlations $(\mathrm{r}=0.47481)$.

\section{Discussion}

Synchronized vigor shoot and root growth are the foremost factor for production of quality transplants in vitro (Mohamed et al., 2007 and 2010). However, the genetic stability of the produced transplants is indispensable in the micropropagation. Therefore, the extensive use of plant growth regulators (PGRs) is not desirable due to a possible adverse effect on genetic stability (Devarumath et al., 2002 and Struik and Wiersema, 2012). For this reason, potato transplants production is usually attained on PGR-free medium (Naik, and Karihaloo, 2007). Conversely, substantial research studies have been conducted on the use of medium

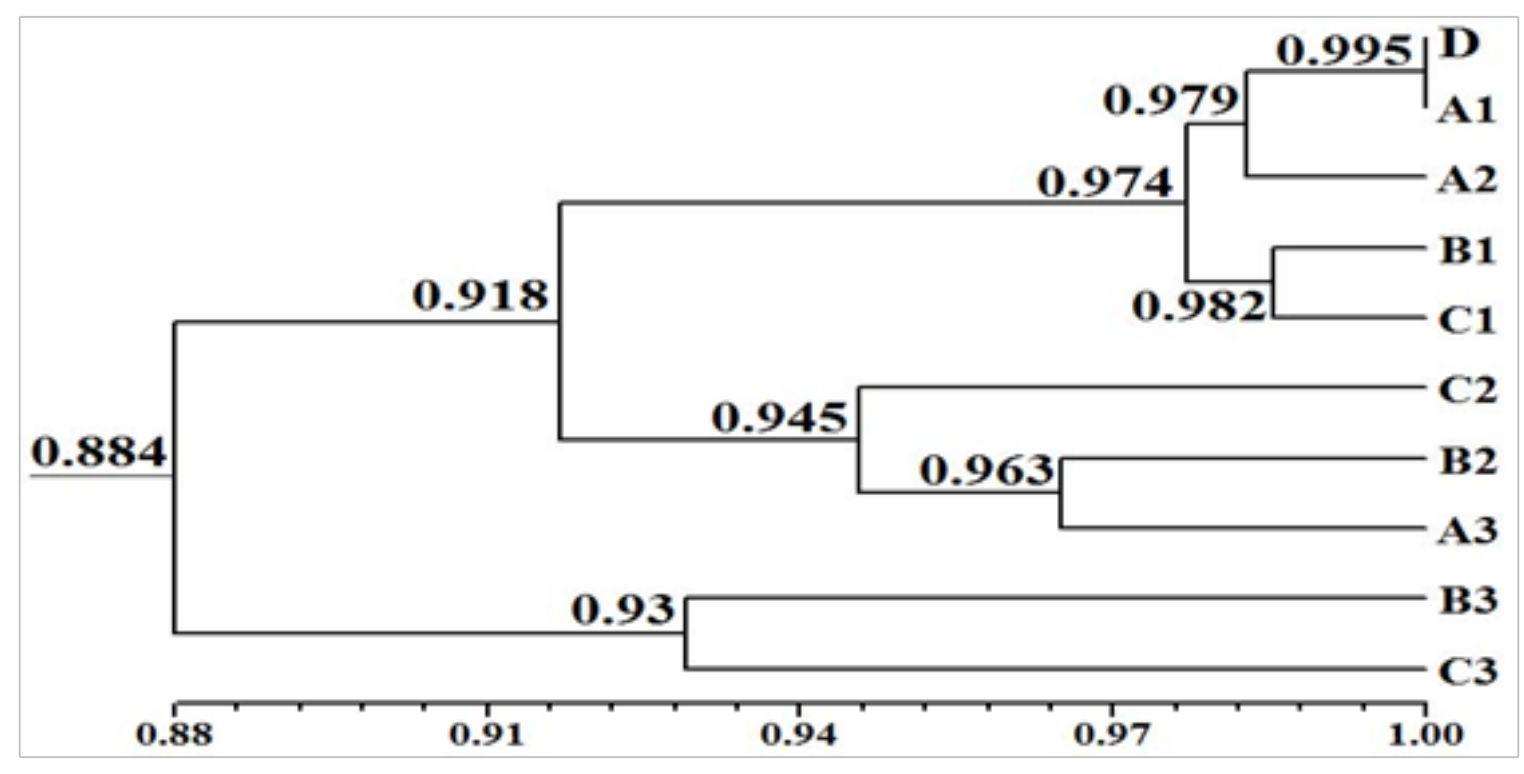

Fig. 13. Dendrogram of donor plant and the proliferated plants developed from combined RAPD, ISSR and SRAP markers data using UPGMA analysis. The scale is based on Dice coefficients of similarity.

Egypt. J. Hort. Vol. 45, No. 2 (2018) 
TABLE 4. Protein patterns of donor plant and the proliferated plants from three cycles of subculture on MS media with different concentrations of BA $(0,0.5$ and $1.0 \mathrm{mg} / \mathrm{l})$.

\begin{tabular}{|c|c|c|c|c|c|c|c|c|c|c|c|}
\hline No & MW & D & A1 & B1 & C1 & A2 & B2 & $\mathrm{C} 2$ & A3 & B3 & C3 \\
\hline 1 & 88.2KD & + & + & + & + & + & + & + & + & + & + \\
\hline 2 & 76.3KD & + & + & + & + & + & + & + & + & + & + \\
\hline 3 & 69.8KD & + & + & + & + & + & - & - & + & - & - \\
\hline 4 & $62.1 \mathrm{KD}$ & + & + & + & + & + & + & + & + & + & + \\
\hline 5 & 54.6KD & + & + & + & + & + & + & + & + & + & + \\
\hline 6 & $50.8 \mathrm{KD}$ & - & - & - & - & - & + & + & - & + & + \\
\hline 7 & 47.2KD & + & + & + & + & + & + & + & + & + & + \\
\hline 8 & 43.4KD & + & + & + & + & + & + & + & + & + & + \\
\hline 9 & 40.4KD & + & + & + & + & + & + & + & + & + & + \\
\hline 10 & 38.0KD & - & - & + & + & - & + & + & - & + & + \\
\hline 11 & 35.4KD & + & + & + & + & + & + & + & + & + & + \\
\hline 12 & 30.6KD & + & + & + & + & + & + & + & + & + & + \\
\hline 13 & 27.6KD & + & + & + & + & + & + & + & + & + & + \\
\hline 14 & 25.2KD & + & + & + & + & + & + & + & + & - & - \\
\hline 15 & 19.5KD & + & + & + & + & + & + & + & + & + & + \\
\hline 16 & 17.4KD & + & + & + & + & + & + & + & + & + & + \\
\hline
\end{tabular}

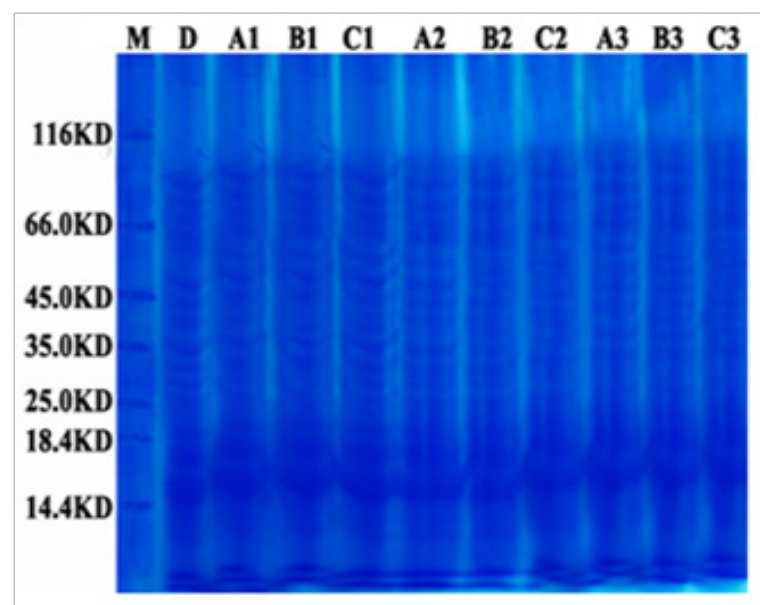

(a)

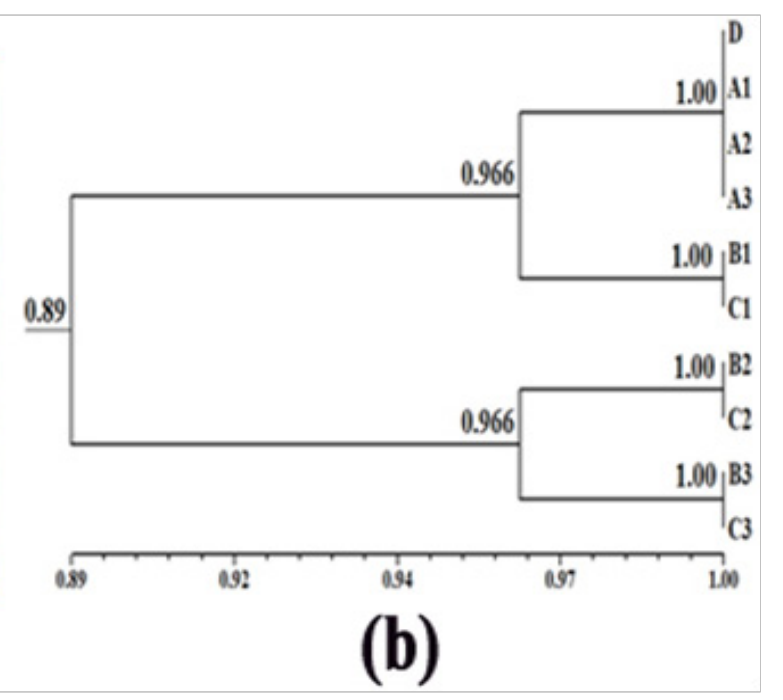

Fig. 14. Protein banding profile (a) of potato donor plants (D) and the proliferated plants (A1, B1, C1, A2, B2, C2, A3, B3 and C3) from three cycles of subculture. Lane $M$ represented the protein marker. Dendrogram (b) developed from protein patterns data using UPGMA analysis developed from protein patterns data using UPGMA analysis for donor plants and the proliferated plants in the different media and subcultures. The scale is based on Dice coefficients of similarity. 
supplements with mostly the cytokinin benzyl adenine (BA), inducing shoot multiplication (Kazemiani, et al., 2012, Liljana et al., 2012, Fufa and Diro, 2013, Hossain et al., 2013 and Kaur et al., 2015). Keeping awareness of extensive use of PGRs, these investigations were using low concentrations of BA (2 mg/l or less).

Generally, BA breaks the apical dominance and consequently shoot branching is stimulated (Mohamed et al., 1991 and 1992 and Tawfik and Mohamed 2005 and 2006). Here, the medium lacking BA occasionally showed axillary branches. On the other hand, cultures on the medium containing BA consistently developed axillary branches. Axillary branches produced on the medium supplemented with BA relative to the medium lacking BA were 3 to 11 folds and 5 to 12 folds for BA $0.5 \mathrm{mg} / 1$ and $1.0 \mathrm{mg} / 1$, respectively. Obviously, the greatest number of single nodes per culture (single nodal yield) was obtained on the medium with BA $1.0 \mathrm{mg} / 1$ followed by the medium contained $0.5 \mathrm{mg} / \mathrm{l}$. The multiplication rates were 3.2, 6.0 and 7.4 for the medium lacking BA and medium-containing BA 0.5 and 1.00 $\mathrm{mg} / \mathrm{l}$, respectively.

Noticeably, roots were observed on the explants grown on the medium lacking BA during all shoot multiplication cycles. On the contrary, roots did not form on the explants grown on the multiplication media containing BA. Difficulty in root formation remained even when the harvested single nodes were subcultured on the medium lacking BA (rooting test). This was most detrimental for transplants production in vitro using the explants excised from culture on the multiplication medium with $1.0 \mathrm{mg} / \mathrm{l} \mathrm{BA}$ added. No roots were formed at all in subculture of explants developed in the third multiplication cycle on the medium with $0.5 \mathrm{mg} / \mathrm{l} \mathrm{BA}$. Those explants harvested from cultures on the multiplication medium with 1.0 $\mathrm{mg} / \mathrm{l}$ BA entirely failed to form roots beyond the first multiplication cycle. In spite of different cultivar, medium and other culture conditions a closely similar result have been reported by other researches (Kazemiani et al., 2012, Liljana et al., 2012, Fufa and Diro, 2013, Hossain et al., 2013 and Kaur et al., 2015).

It is worth to mention that a reduction in the third propagation cycle also occurred in rooting of cultures incessantly grown on the medium lacking BA. Therefore, BA cannot be considered the only primary causal factor for root formation disruption especially as BA was utilized here at low concentration. It is speculated that most likely the inhibition of rooting can largely be attributed to elevated ethylene level inside culture jars. Potato tissue culture is reported to be sensitive to ethylene accumulation in the culture vessel (Naik \& Karihaloo, 2007 and Ehsanpour \& Nejati, 2013). Ethylene that totally prevented root formation and development was reported by Mingo-Castel et al. (1976) and the gaseous plant hormone ethylene reduces lateral root formation and enhances polar transport of the hormone auxin (Lewis, 2011). Ethylene accumulation can show differential symptoms on potato in vitro plants including epinasty or hyperhidricity (Sandra and Maira, 2013). The effect of ethylene on root growth is largely mediated by the regulation of the auxin biosynthesis and transport-dependent local auxin distribution (Růžička et al., 2007). The analysis conducted by Street et al. (2015) suggested that multiple phytohormones interact to control root growth, including ethylene, which is primarily known for its role in controlling root cell elongation. Ethylene also negatively regulates cell proliferation at the root meristem. Additional analysis indicated that ethylene signaling contributes but is not required for cytokinin to inhibit activity of the root meristem. Accordingly, in the current assessment, the effect of BA in the medium of shoots multiplication may have been carried over to subcultures and at least partially contributed to the inhibition of root formation. While BA was such an influential factor, the effect of culture cycle was relatively missing or marginal and inconsistent.

Phytohormones regulate plant metabolism directly at molecular, cytological levels as well as in a whole plant (Posmyk and Szafranska, 2016) and often act as a signaling molecule. They can modify plant natural program. In addition, tissue culture-derived variation may be induced under the influence of certain plant growth regulators and in vitro conditions. Here, the approach of molecular and biochemical analyses has provided signs rationalizing a genetic background for the aforementioned observed phonotypical alterations occurred during potato shoot multiplication cycles. The Mantel test values between distance matrices of phenotypic matrices and combined matrices of molecular markers and biochemical markers showed positive and significant correlations ( $\mathrm{r}=$ 0.47481 ). This indicates that phenotypic variation occurred on MS media with or without benzyl

Egypt. J. Hort. Vol. 45, No. 2 (2018) 
adenine for several cycles of sub-culture seemed to be associated with molecular (DNA markers) and biochemical (protein patterns) changes which were observed in this study. In harmony with the phonotypical records, particularly for root formation, soluble protein patterns dendrogram grouped the donor plant, all proliferated shoots from the three multiplication cycles of sub-culture on MS control medium (lacking BA) and shoots proliferated from sub-culture-1 on MS containing 0.5 and $1.0 \mathrm{mg} / 1 \mathrm{BA}$ in group- 1 . Within this group, the donor plants were closely related to all proliferated plants from the three cycles of sub-culture on control medium. The proliferated plants from the second and third cycles of subculture on MS media containing BA at 0.5 and $1.0 \mathrm{mg} / 1$ were clustered in group-2. The presented protein banding has shown details on the role of BA and repeated multiplication cycles. These include: bands at $69.8 \mathrm{KD}$ and $50.8 \mathrm{KD}$ which suggest a more pronounced effect of BA appeared with increasing the number of shoot proliferation cycles and protein bands at $38.0 \mathrm{KD}$ and $25.2 \mathrm{KD}$ which suggest a role of BA in altering in vitro potato shoot phenotype.

In many somaclonal studies performed on different plant species including banana (Sheidai et al., 2008), cotton (Sheidai et al., 2008), and olive (Peyvandi et al., 2010 and Farahani et al., 2011), there are reports that genetic diversity between donor plants and their in vitro proliferated plants increase by increasing the number of subcultures and in existence of certain PGRs. Cluster analysis here based on combined data of three molecular marker systems showed more common loci between donor plants and their proliferated plants of the first subculture, while common loci are of less occurrence among the second and third subculture plants. Further, the studied marker systems have suggested that the presence of BA in media may induce mutation in DNA sequence. These findings supported by the presence and/ or absence of some bands in the proliferated shoots on MS media contained benzyl adenine. For example, band at molecular size of $244 \mathrm{bp}$ generated by SRAP-1 primer was detected in all regenerated plants from the three cycles of subculture on MS media contained $0.5 \mathrm{mg} / 1$ and 1.0 $\mathrm{mg} / \mathrm{l} \mathrm{BA}$, while this band did not appear in the donor plants and all proliferated plants grown on the control medium (lacking BA). Also, DNA band at molecular size of 576 bp generated by OPD02 primer was detected only in the donor plant and all plants proliferated on control medium while was not found in all proliferated shoots on MS media containing benzyl adenine.

Evidences indicating that the increase in the number of subculture can lead to variations in DNA sequence at different regions in genome which have been also found out in the assessment of the different marker systems. For example, the bands at molecular sizes of $447 \mathrm{bp}$ and 259 bp generated by RAPD primers OPA01 and the SRAP-3, respectively, were detected in plants regenerated from subculture-2 and subculture-3 on different concentrations of BA, while not found in the donor plants and all proliferated shoots of subculture-1. Furthermore, DNA fragments of $782 \mathrm{bp}$ (OPA01), 320bp (HB13) and $205 \mathrm{bp}$ (HB12) were found only in the tissues of cultures grown on both concentrations of BA in the third cycle of subculture. On the other hand, the DNA fragments at molecular size of $494 \mathrm{bp}$ (HB08), 292 bp (HB12), 361 bp (SRAP-1) and 474 bp (SRAP-3) were absent in plants proliferated on the two concentrations of $\mathrm{BA}$ in the third cycle of subculture only. Further detections support the influence of BA concentrations on triggered variations between tissue of proliferated shoot culture in the same cycle of subculture or between different cycles of subculture can be found in the presence of DAN band at molecular weight 634 bp amplified by OPA13 primer in tissue produced on medium with $1.0 \mathrm{mg} / \mathrm{l} \mathrm{BA}$ at the three cycles of sub-culture while not found in tissues proliferated on control medium or MS media with $0.5 \mathrm{mg} / 1$ BA; also DNA bands at molecular size of $290 \mathrm{bp}$ (UBC09) and 283 bp (OPA07)

\section{Conclusion}

In conclusion, considering the control of ethylene accumulation may be beneficial while use of $\mathrm{BA}$ is not advisable in the in vitro propagation of the potato cv. Cara. Check of genetic stability at short intervals is feasible and should be given an attention.

Acknowledgment:The authors would like to deeply appreciate the support provided by Faculty of Agriculture, Assiut University, Egypt.

Funding statements: The authors received no external funding for this study.

Conflict of interest: The authors declare that they have no conflict of interest. 


\section{References}

Ahmad, Z., Shahzad, A., Sharma, S. and Parveen, S. (2018) Ex vitro rescue, physiochemical evaluation, secondary metabolite production and assessment of genetic stability using DNA based molecular markers in regenerated plants of Decalepis salicifolia (Bedd. ex Hook.f.) Venter. Plant Cell, Tissue and Organ Culture, 132, 497-510.

Devarumath, R.M., Nandy, S., Rani, V., Marimuthu, S., Muraleedharan, N. and Rania, S.N. (2002) RAPD, ISSR and RFLP fingerprints as useful markers to evaluate genetic integrity of micropropagated plants of three diploid and triploid elite tea clones representing Camellia sinensis (China type) and C. assamica ssp. Assamica (Assam-India type). Plant Cell Reports, 21(2), 166-173.

Dice, L.R. (1945) Measures of the amount of ecologic association between species. Ecology, 26, 297-302.

Dodds, J.H. (1988) Tissue culture technology: practical application of sophisticated methods. Am. Potato J., 65, 167-180.

Donnelly, D.J., Coleman, W.K. and Coleman, S.E. (2003) Potato microtuber production and performance: A review. Amer. J. of Potato Res., 80, 103-115.

Ehsanpour, A.A. and Nejati, Z. (2013) Effect of nanosilver on potato plant growth and protoplast viability. Biological Lett., 50(1), 35-43.

Farahani, F., Yari, R., Sheidai, M. (2011) Somaclonal variation in Dezful cultivar of olive (Olea europaea subsp. europaea). GeneConserve, 40, 216-233.

Fufa, M. and Diro, M. (2013) Response of potato cultivars to in vitro multiplication. Wudpecker Journal Agricultural Research, 2(11), 299-302.

Golmirzaie, A.M., Buendia, S., Espinoza, J. and Ortiz, R. (2004) Open pollinated offspring for producing potatoes from true seed. Tropiculture, 22(4), 191-198.

Gomez, K.A. and Gomez, A.A. (1984) “ Statistical Procedures for Agricultural Research “, $2^{\text {nd }}$ ed., Wiley, New York, 680 p.

Hasan, A.A. (1999) "Potato Production", Al-Dar AlArabia for Publication and Distribution, Cairo (in Arabic) 446 p.

Hoque, M.E. (2010) In vitro tuberization in potato (Solanum tuberosum L.). Plant Omics Journal (POJ), 3(1), 7-11.

Egypt. J. Hort. Vol. 45, No. 2 (2018)
Hossain, M.A., Nasiruddin, K.M. and Abu Kawochar, M. (2013) Effect of 6-benzyl aminopurine (BAP) on meristem culture for virus free seed production of some popular potato varieties in Bangladesh. African J. Biotechnology, 12(18), 2406-2413.

Kanwal, A., Ali, A. and Shoaib, K. (2006) In Vitro microtuberization of potato (Solanum tuberosum L.) cultivar Kuroda-- A New Variety in Pakistan. Int. J. Agri. Biol., 8 (3), 337-340.

Kaur, M., Kaur, R., Sharma, C., Kaur, N. and Kaur, A. (2015) Effect of growth regulators on micropropagation of potato cultivars. African $\mathrm{J}$. Crop Sci., 3(5), 162-164.

Kazemiani, S., Motallebi-Azar, A., Mohaddes, N., Kiommasy, F., Yarmohammadi, F. and Etedali, F. (2012) Effect of different concentrations of sucrose and BAP on shoot proliferation on MS strength basal media in potato cv. Agria. South Western Journal of Horticulture, Biology and Environment, 3 (1), 63-72.

Laemmli, U.K. (1970) Cleavage of structural proteins during the assembly of the head of bacteriophage T4. Nature, 227, 680-685.

Lewis, D.R., Negi, S., Sukumar, P. and Muday, G.K. (2011) Ethylene inhibits lateral root development, increases IAA transport and expression of PIN3 and PIN7 auxin efflux carriers. Development, 138, 3485-3495.

Liljana, K.G., Mitrev, S., Fidanka, T. and Mite, I. (2012) Micropropagation of potato (Solanum tuberosum L). Electronic J. Biology, 8 (3), 45-49

Mantel, N. (1967) The detection of disease clustering and a generalized regression approach. Cancer Research, 27(2), 209-220.

Mingo-Castel, A.M., Smith, O.E. and Kumamoto, J. (1976) Studies on the carbon dioxide promotion and ethylene inhibition of tuberization in potato explants cultured in vitro. Plant Physiol., 57, 480-485.

Mohamed, M.F. (1998) In vitro propagation of an Egyptian landrace of green pepper and breeding for tolerance to heat and drought stresses. Acta Hort., 457, 243-253.

Mohamed, M.F. and Tawfik A.A. (2009) A medium derived from natural extract for conservation of meristematic cells and tissues of plant germplasm in gene banks and propagation nuclei in commercial production of horticultural crop transplant. Patent number 24383, April 2009, Academy of science \& Technology, Egypt. 
Mohamed, M.F., Abdalla, M.M.A. and Damarany, Jr. (2007) Differential axillary-bud proliferation responses of two sweet potato cultivars to benzyl adenine and thidiazuron. Assiut Univ. Bull. Environ. Res., 10 (2), 21-30.

Mohamed, M.F., Abdalla, M.M.A. and Damarany, Jr. (2010) In vitro propagation responses of apical shoot vs. stem single-node microcuttings in sweet potato (Ipomoea batatas L.) International Conference for Environ. and Devel. in The Arab World, 2-23 March 2010.

Mohamed, M.F., Read, P.E. and Coyne, D.P. (1991) In vitro response of bean (Phaseolus vulgaris L.) cotyledonary explants to benzyladenine in the medium. Plant Growth Regul. Soc. Amer. Quarterly, 19, 19-26.

Mohamed, M.F., Read, P.E. and Coyne, D.P. (1992) lant regeneration from in vitro culture of embryonic axis explants in common and tepary beans. J. Amer. Soc. Hort. Sci., 117 (2), 332-336.

Mohapatra, P P. and Batra, V.K. (2017) Tissue culture of potato (Solanum tuberosum L.): A review. Int. J. Curr. Microbiol. Appl. Sci., 6 (4), 489-495.

Murashige, T. and Skoog, F. (1962). A revised medium for rapid growth and bioassays with tobacco tissue cultures. Physiol. Plant., 15, 473-97.

Murray, M.G. and Thompson, W.F. (1980) Rapid isolation of high molecular weight plant DNA. Nucleic Acids Res., 8 (19), 4321-4325.

Naik, P.S. and Karihaloo, J.L. (2007) “Micropropagation for Production of Quality Potato Seed in AsiaPacific. Asia-Pacific Consortium on Agricultural Biotechnology, New Delhi, India, 54 p.

Peyvandi, M., Farahzadi, H.N., Arbabian, S., Noormohammadi, Z. and Hosseini-Mazinani, M. (2010) Somaclonal variation among somaticembryo derived plants of Olea europaea L "cv. Kroneiki”. J. Sci., Islamic Rep. Iran, 21 (1), 7-14.

Posmyk, M.M. and Szafranska, K. (2016) Biostimulators: A new trend towards solving an old problem. Frontiers in Plant Science, 7, 1-6.

Rohlf, F.J. (2000) Statistical power comparisons among alternative morphometric methods. Amer. J. Phys. Anthropol., 111, 463-478.

Růžička, K., Ljung, K., Vanneste, S., Podhorská, R., Beeckman, T., Friml, J. and Benková, E. (2007) Ethylene regulates root growth through effects on auxin biosynthesis and transport-dependent auxin distribution. The Plant Cell, 19, 2197-2212.
Sandra, A.T. and Maira, O. (2013) Effect of culture medium consistence and silver nitrate on micropropagation of two potato (Solanum tuberosum L.) cultivars. Rev. Colomb. Biotecnol., 15 (2), 55-62.

Sheidai, M., Aminpoor, H., Noormohammadi, Z. and Farahani, F. (2008) RAPD analysis of somaclonal variation in banana (Musa acuminate L.) cultivar Valery. Acta Biologica Szegediensis, 52(2), 307311.

Sheidai, M., Yahyazadeh, F., Farahanei, F. and Noormohammadi, Z. (2008) Genetic and morphological variations induced by tissue culture in tetraploid cotton (Gossypium hirsutum L.). Acta Biologica Szegediensis, 52 (1), 33-38.

Srivastava, A.K., Diengdoh, L.C., Rai, R. and Bag, T.K. (2012) Tissue Culture - Technology Harnessed for Potato Seed Production. Keanean J. Sci., 1, 80-86.

Street, I.H., Aman, S., Zubo, Y., Ramzan, A., Wang, X., Shakeel, S.N., Kieber, J.J. and Schaller, G.E. (2015) Ethylene inhibits cell proliferation of the Arabidopsis root meristem. Plant Physiology, 169 (1), 338-350.

Struik, P.C. and Wiersema, S.G. (2012) “ Seed Potato Technology “, Wageningen Academic Publishers, The Netherlands, pp. 382.Tawfik, A.A. and Mohamed, M.F. (2005). Organogenic response of Salvia officinals L. to dark preconditioning, thidiazuron and benzyl adenine. Plant Growth Regul. Soc. Amer. Quarterly, 33, 125-133.

Tawfik, A.A. and Mohamed, M.F. (2006) In vitro cloning of two cumin landrace lines via shoot-tip culture. J. Hort. Sci. Biotech., 81, 264-268.

Upadhya, M.D. (1994) True potato seed: propagule for potato production in the 21 st century. In: G.S. Shekawat, S.M. Paul Khurana, S.K. Pandey and V.K. Chandra (Ed.), pp. 15-22, Potato: Present and Future. Indian Potato Association, Shimla, India.

(Received 03/06/2018; accepted $11 / 06 / 2018$ 


\section{التغيرات المظهرية والجزيئية فى البطاطس صنف كارا تحت تأثير البنزيل أدنين ودورات الإكثار داخل الأنابيب \\ محمد فؤاد محمد * ، بهاء الاين السبا عبد الفتاح *** ، داليا محمود طنطاوي ناصف * ، ، محمد حسام

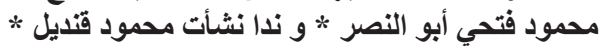 \\ *قمم الخضر - كلية الزر اعة - جامعة أسيوط و ** فسم الور اثنة ـ كلية الزر اعة ـ جامعة أسيوط - أسيوط}

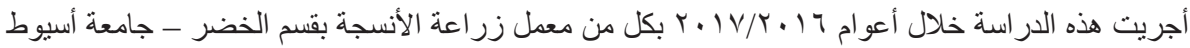

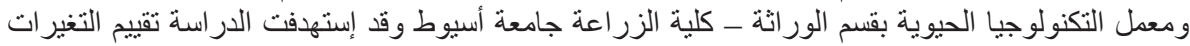

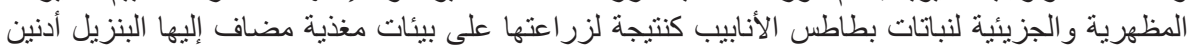

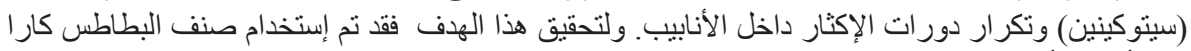

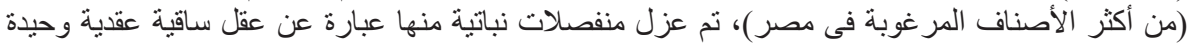

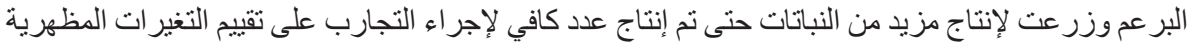

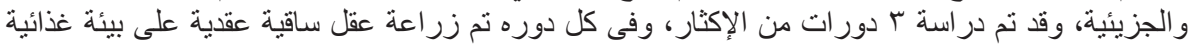

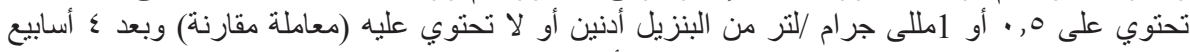

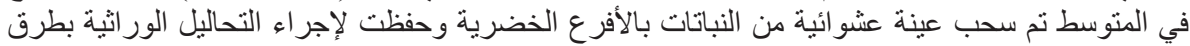

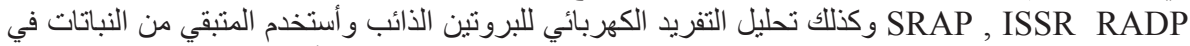

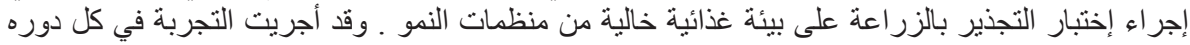

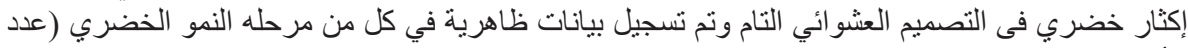

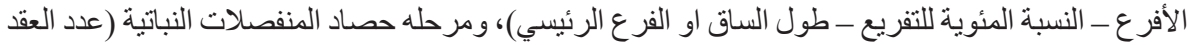
الساقية العقدية) ومرحله إختبار التجذير (النسبه المئويه للتجذير و عدد الجذور على النبات).

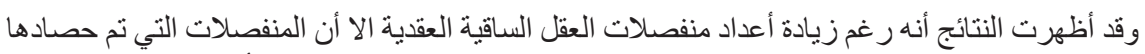

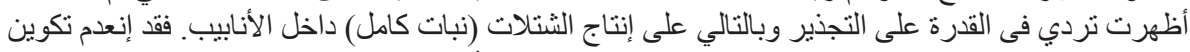

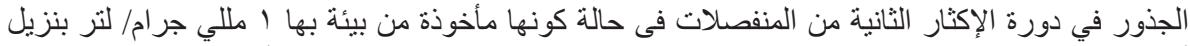

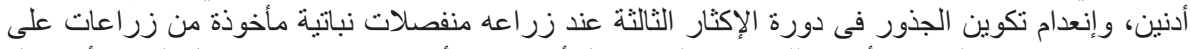

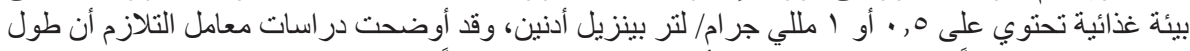

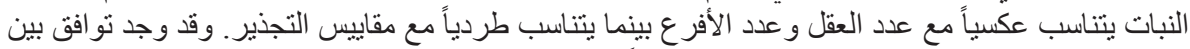

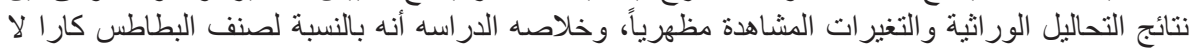

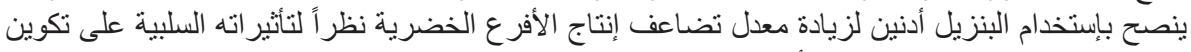

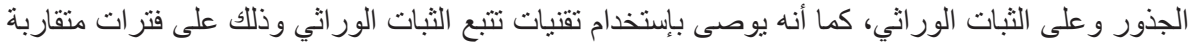

